\title{
Recommendations on chronic constipation (including constipation associated with irritable bowel syndrome) treatment
}

\author{
Pierre Paré MD FRCPC FACG ${ }^{1}$, Ronald Bridges MD FRCPC ${ }^{2}$, Malcolm C Champion MB FRCP(UK) FRCPC ${ }^{3}$, \\ Subhas C Ganguli MD FRCPC MSc ${ }^{4}$, James R Gray MD FRCPC ${ }^{5}$, E Jan Irvine MD FRCPC $\mathrm{MSC}^{6}$, \\ Victor Plourde MD CSPQ MSc PhD ${ }^{7}$, Pierre Poitras MD FRCPC ${ }^{8}$, Geoffrey K Turnbull MD FRCPC ${ }^{9}$, \\ Paul Moayyedi BSc MB ChB PhD MPH FRCP(London) FRCPC ${ }^{10}$, Nigel Flook MD CCFP FCFP ${ }^{11}$, \\ Stephen M Collins MC MBBS FRCP(UK) FRCPC ${ }^{12}$
}

\begin{abstract}
P Paré, R Bridges, MC Champion, et al. Recommendations on chronic constipation (including constipation associated with irritable bowel syndrome) treatment. Can J Gastroenterol 2007;21(Suppl B):3B-22B.
\end{abstract}

\begin{abstract}
While chronic constipation (CC) has a high prevalence in primary care, there are no existing treatment recommendations to guide health care professionals. To address this, a consensus group of 10 gastroenterologists was formed to develop treatment recommendations. Although constipation may occur as a result of organic disease, the present paper addresses only the management of primary CC or constipation associated with irritable bowel syndrome. The final consensus group was assembled and the recommendations were created following the exact process outlined by the Canadian Association of Gastroenterology for the following areas: epidemiology, quality of life and threshold for treatment; definitions and diagnostic criteria; lifestyle changes; bulking agents and stool softeners; osmotic agents; prokinetics; stimulant laxatives; suppositories; enemas; other drugs; biofeedback and behavioural approaches; surgery; and probiotics. A treatment algorithm was developed by the group for CC and constipation associated with irritable bowel syndrome. Where possible, an evidence-based approach and expert opinions were used to develop the statements in areas with insufficient evidence. The nature of the underlying pathophysiology for constipation is often unclear, and it can be tricky for physicians to decide on an appropriate treatment strategy for the individual patient. The myriad of treatment options available to Canadian physicians can be confusing; thus, the main aim of the recommendations and treatment algorithm is to optimize the approach in clinical care based on available evidence.
\end{abstract}

Key Words: Chronic constipation; Irritable bowel syndrome; Normal transit constipation; Obstructive defecation; Primary functional constipation; Slow transit constipation

\section{Des recommandations au sujet du traitement de la constipation chronique ( $\mathrm{y}$ compris celle associée au syndrome du côlon irritable)}

La prévalence de la constipation chronique (CC) est élevée en soins primaires, mais il n'existe pas de recommandations de traitement pour orienter les professionnels de la santé. Pour régler cette lacune, on a formé un groupe consensuel de 10 gastroentérologues afin d'élaborer des recommandations de traitement. Certains cas de constipation découlent d'une maladie organique, mais le présent article ne porte que sur la prise en charge de la CC primaire ou sur la constipation reliée au syndrome du côlon irritable. On a créé le groupe consensuel final et établi les recommandations d'après le processus exact de l'Association canadienne de gastroentérologie dans les domaines suivants : épidémiologie, qualité de vie et seuil de traitement, définitions et critères diagnostiques, modifications au mode de vie, agents gonflants et laxatifs émollients, agents osmotiques, procinétiques, laxatifs stimulants, suppositoires, lavements, autres médicaments, rétroaction biologique (biofeedback) et approches behaviorales, chirurgie et probiotiques. Le groupe a conçu un algorithme de traitement de la CC et de la constipation associée au syndrome du côlon irritable. Dans la mesure du possible, elle a privilégié des démarches probantes et des avis d'experts pour élaborer des énoncés dans les domaines où les données étaient insuffisantes. Souvent, on ne connaît pas vraiment la nature de la physiopathologie sous-jacente à la constipation, et il peut être délicat pour les médecins de choisir une stratégie de traitement pertinente pour un patient donné. La myriade de possibilités de traitement offerte aux médecins canadiens peut susciter la confusion. Les recommandations et l'algorithme de traitement visent donc à optimiser la démarche de soins cliniques d'après les données disponibles.

C onstipation may be primary or secondary to other medical problems, including neurological, metabolic or endocrine diseases. This paper addresses chronic constipation (CC) or constipation associated with irritable bowel

syndrome (IBS-C). Only the management of primary functional constipation is discussed in the present paper. Considering the pathophysiology of constipation, this condition may be classified as slow transit (ST), normal transit (NT)

${ }^{1}$ Université Laval and Division of Gastroenterology, CHAUQ - Hopital St-Sacrement, Quebec City, Quebec; ${ }^{2}$ Division of Gastroenterology,

University of Calgary, Calgary, Alberta; ${ }^{3}$ Department of Gastroenterology, Ottawa Hospital, and University of Ottawa, Ottawa, Ontario;

${ }^{4} \mathrm{McM}$ aster University and Department of Gastroenterology, St Joseph's Healthcare, Hamilton, Ontario; ${ }^{5}$ Division of Gastroenterology,

University of British Columbia, Vancouver, British Columbia; ' ${ }^{6}$ niversity of Toronto, and Division of Gastroenterology, St Michael's Hospital,

Toronto, Ontario; ${ }^{7}$ Université de Montréal, Montreal, Quebec; ${ }^{8} \mathrm{CHUM} \mathrm{St} \mathrm{Luc} \mathrm{and} \mathrm{Université} \mathrm{de} \mathrm{Montréal,} \mathrm{Montreal,} \mathrm{Quebec;}{ }^{9}$ Dalhousie

University, Halifax, Nova Scotia; ${ }^{10}$ Division of Gastroenterology, McMaster University, Hamilton, Ontario; ${ }^{11}$ Misericordia Community

Hospital $\mathcal{E}$ Health Center, and University of Alberta Hospital, Edmonton, Alberta; ${ }^{12}$ Faculty of Health Sciences, McMaster University,

Hamilton, Ontario

Correspondence: Dr Pierre Paré, Université Laval and CHAUQ-Hôpital St-Sacrement, 1050, Chemin Ste-Foy, Quebec City, Quebec G1S 4 L8.

Telephone 418-682-7511 ext 4603, fax 418-682-7855, e-mail pierre.pare@cha.quebec.qc.ca

Received for publication December 7, 2006. Accepted March 5, 2007 
or constipation due to obstructed defecation (OD). The frequency distribution of these abnormalities within any given group of patients varies. A North American study (1) showed that $59 \%$ of cases were NT, $13 \%$ were ST and $25 \%$ were OD, with only $3 \%$ of cases exhibiting a mixed ST/OD picture. Similar results were reported in a Thai study (2), which observed that $13 \%$ of patients had ST, $29 \%$ had OD, $11 \%$ had a mixed classification of ST/OD and the remainder (47\%) had NT. In general, NT constipation is associated with IBS-C, although there is up to a $50 \%$ overlap between IBS-C and ST constipation. There is also a $10 \%$ to $13 \%$ overlap between ST and OD constipation subgroups (3).

\section{ST constipation}

Manometric studies have identified a reduction in the frequency of high-amplitude propagated contractions in the colon of patients with ST constipation when compared with nonconstipated subjects (4-7). The persistence of some low-amplitude propulsive activity may represent a partial compensatory mechanism in these patients (7). Similar findings were demonstrated in patients with IBS-C, although this is traditionally associated with NT $(6,7)$. Scintigraphic measurements indicate that ST is more frequent in the left colon and sigmoid than in the transverse and ascending colon (8). A loss of coordination between contractile activity in the rectum and sigmoid colon has also been implicated in ST constipation (9). Reductions in rectal sensory thresholds may also contribute to ST constipation (10). Motility changes in ST constipation are not limited to the colon and rectum; abnormalities have also been documented in the stomach and jejunum. In one study (11), almost one-third of patients with ST constipation showed evidence of abnormal jejunal motility. Other studies (12-14) have demonstrated delayed gastric emptying and impaired gastric accommodation, which do not necessarily improve after colectomy for severe ST constipation. This raises the possibility that ST constipation may be part of a more global motor disorder.

The nature of underlying pathology in ST constipation is unclear. Several studies (15-17) have identified a loss of interstitial cells of Cajal throughout the colon in patients with ST constipation. In some studies, this was accompanied by a reduction in myenteric ganglia (17) or a reduction in nerves that contain vasoactive intestinal peptide or nitric oxide synthase, which suggests a loss of inhibitory or relaxatory neural input to the ascending colon (18). An in vitro study of colonic tissue, however, showed no decrease in nitric oxide synthasepositive nerves, and responses to exogenous nitric oxide were similar to controls in ST constipated patients $(14,19)$. Other abnormalities include a loss of glial cells (20) and a reduction in serotonin receptor immunoreactivity in the muscular mucosa and circular muscle in colonic inertia patients. Although serotonin-containing cells are increased in number in ST constipation, the serotonin receptor(s) immunoreactivity level is lower in muscular mucosa and circular muscle, particularly in the left colon $(21,22)$.

\section{OD}

The subgroup of patients with OD is quite heterogeneous in terms of the underlying pathophysiology (23). Functional outlet obstruction may occur as a result of anal sphincter dysfunction or pelvic floor muscle dyssynergia, although in a minority of patients, structural abnormalities - such as intussusception, excessive perineal descent and obstructing rectoceles - may also cause OD. Behavioural issues are important in this type of constipation and include sexual abuse (24), as well as the conscious frequent suppression and postponement of the urge to defecate (25). Paradoxical contraction of the anal sphincter during defecation is referred to as anismus, and while it has been shown to be associated with a history of abuse (24), its role in the pathophysiology of constipation is often exaggerated $(26,27)$ because this finding can occur in healthy subjects during the performance of anorectal motility testing (26). OD can also arise as a result of impaired rectal sensation $(26,28)$, which occurs in the presence of normal rectal compliance (29). Colonic motor abnormalities may also contribute to obstructed defecography. In normal subjects, there is an enhancement of both the frequency and the amplitude of a propagated activity in the distal colon just before defecation. This predefecatory augmentation is lost in some patients with OD (30).

\section{NT constipation}

As a subgroup, patients with NT constipation constitute the least clearly defined population. By definition, colonic transit is normal, and there is no evidence of functional outlet obstruction on testing (31). Typically, IBS-C patients fall into this category. Some studies on these patients have shown that there is an increase in rectal perception thresholds to distension (32-34). According to studies using a barostat, this increased tolerance to distension is due to impaired sensory perception rather than to altered compliance or tone in the rectal wall (35). This distinguishes IBS-C patients from other IBS subgroups in which rectal hypersensitivity is a common finding (36). Thus, the pathophysiology of NT constipation is complicated and is likely to be heterogenous.

\section{METHODS}

The development of the Recommendations on CC (including IBS-C) Treatment followed a procedure similar to that outlined by the Canadian Association of Gastroenterology (37). Statements reflecting the current understanding of and positions on different aspects of CC and IBS-C management were developed using the process outlined below.

\section{Determination of need for recommendations}

Two physician surveys conducted by the continuing medical education division of Laval University in Quebec revealed that there was a need for recommendations on CC (including IBS-C) treatment among Canadian physicians. In a survey on IBS-C conducted between August and September 2004, questionnaires were sent to 250 Canadian family physicians. Of 46 completed surveys, 40 physicians $(87 \%)$ responded that they routinely managed patients with chronic or episodic abdominal pain or discomfort, bloating and IBS-C. In a second survey, conducted between October and November 2005, questionnaires were sent to 250 Canadian family physicians, of which 50 were completed. This survey confirmed that $87 \%$ of physicians routinely managed patients with $\mathrm{CC}$ and supported the need for guidelines. Objectives were then approved by both co-Chairs (Drs S Collins and P Paré) for a working group to establish these recommendations.

\section{Membership of the consensus group}

A consensus group of 10 gastroenterologists selected from across the country was formed (see Appendix). Members were chosen for their expertise in diverse areas in gastroenterology. A series of conferences were then organized, totalling four days of face-to-face 
meetings and one teleconference between November 2005 and May 2006. As part of the process, a general practitioner (GP) was invited to join the group to add a GP's perspective to the recommendations to ensure their usefulness in primary care, as well as in specialist practice. A nonvoting Chair was also present for the final step to chair the voting process (see Appendix).

Determination of clinically relevant issues

Clinically relevant topics or issues pertaining to CC and IBS-C treatments were identified through a literature review by members of the consensus group. Eleven different topics or treatment categories were identified, and each was then assigned to a specific group member to research and create recommendations. Recommendations were developed for the following areas: epidemiology, quality of life, pathophysiology and threshold for treatment; definitions and diagnostic criteria; bulking agents and stool softeners; stimulant laxatives; osmotic agents; prokinetics; other drugs; lifestyle changes; biofeedback and behavioural approaches; and alternative approaches.

\section{Nature and extent of background preparation}

Recommendations were evidence-based when literature was available. Supporting evidence was primarily retrieved through a MEDLINE, PubMed or EMBASE search, or Cochrane review on each topic. Search terms included the following: 'chronic constipation', 'irritable bowel syndrome', 'biofeedback', 'behavioural therapy', 'tegaserod', 'domperidone', 'erythromycin', 'lactulose', 'polyethylene glycol', 'milk of magnesia', 'laxatives', 'suppositories', 'enemas', 'epidemiology', 'quality of life', 'antispasmodics', 'bisacodyl', 'misoprostol', 'trimebutine', 'psyllium', 'ispaghula', 'bulking agents', 'docusate', 'methylcellulose', 'mineral oil', 'paraffin oil', 'diet', 'lifestyle', 'intestine function', 'gastrointestinal symptoms' and 'side effects'. Articles were restricted to English-language full publications of research in adults between 1966 and April 2006. Evidence from abstracts was not used to formulate recommendations. The evidence and recommendations compiled by individual consensus group members were then presented to the group for discussion.

\section{Consensus process}

The group followed a modified Delphi consensus process (38) in a fashion similar to that outlined in the Canadian Association of
TABLE 1

Voting options available to participants
a. Accept completely
b. Accept with some reservation
c. Accept with major reservation
d. Reject with reservation
e. Reject completely

Statement accepted where a minimum of $80 \%$ of participants voted a or $b$

Gastroenterology document (37). A series of statements were voted on using a five-point Likert scale (Table 1).The grade of evidence was also voted on according to the quality of the data available (Table 2) (39). Recommendations were accepted only if $80 \%$ of participants voted for 'accept completely' or 'accept with some reservations'. If less than $80 \%$ of participants voted for these two categories, the objections were discussed, and either the conflict was resolved or the statement was revised. The recommendation was then voted on again.

Defining the statements for recommendations

Two meetings were held in May 2006 to finalize the statements to be included in the final recommendations document. At both conferences, participants presented their final statements or recommendations for the topics they were assigned, along with a summary of their supporting evidence. After presentation of relevant data, the quality of the evidence, strength of recommendation and level of consensus were graded by participants according to accepted principles. An anonymous vote was passed on all proposed statements. Along with the 10 specialists in the consensus group, a GP representative and a nonvoting Chair were present for the final summary and grading of the evidence. Neither the Chair nor the GP representative voted on the recommendations.

Report preparation procedure and format

A treatment algorithm for CC and IBS-C was created based on the recommendations that achieved a voting consensus by the group (Figure 1 [see page 16B]). The group members then drafted the final manuscript for the Recommendations on CC (including IBS-C) Treatment presented here. All members of

\section{TABLE 2}

\section{Classification of recommendations}

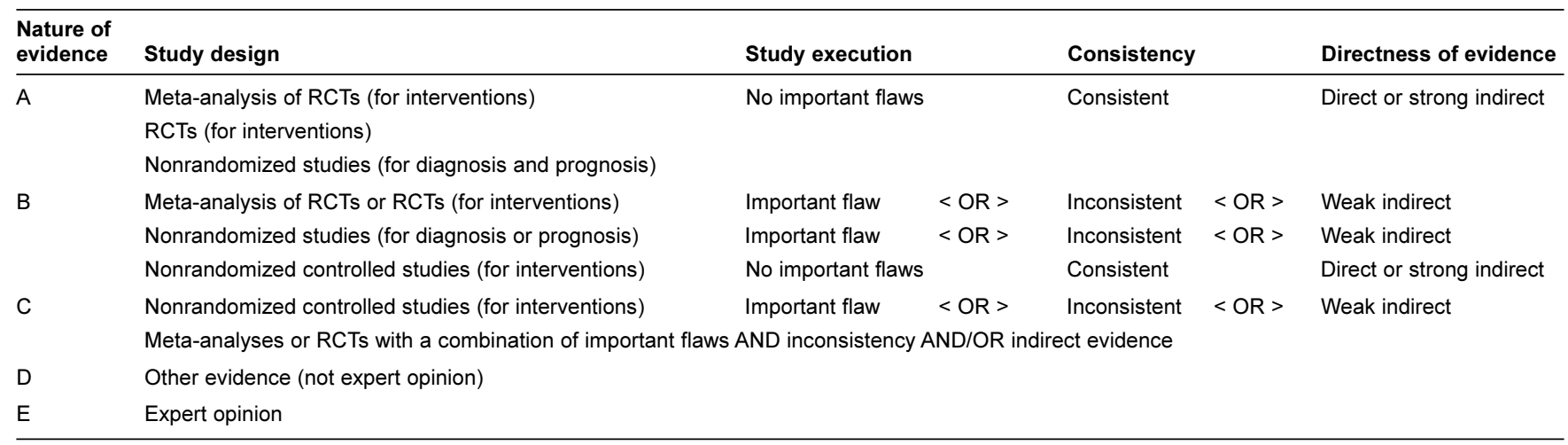

Exceptions that can alter the quality of grading: sparse data (few events); use of data not in its initial randomization or apparent publication bias can lower the quality; a very strong association can raise the quality. Coding notes: important flaws occur when the highest standards of research that could be achieved by a study are not applied. Consistency occurs at two levels - design: consistent methods, patients, outcomes; and statistical: a test of homogeneity of a summary estimate when the level of design consistency is acceptable and meta-analysis appropriate. Directness: direct evidence: relevant patient benefits and harms are measured in studies; strong indirect: the surrogate end point is strongly related to desirable end points, or direct evidence is available for a sufficiently related patient group; weak indirect: the relationship between the study outcomes and patient benefits or harms is insufficient. RCT Randomized controlled trial 
the consensus group and the GP representative approved the final draft of the recommendations, the treatment algorithm and this supporting article.

\section{EPIDEMIOLOGY}

Statement 1: The estimated prevalence of CC varies according to the definitions used: $27 \%$ when self-reported and $16 \%$ when based on the presence of two or more symptoms. For all definitions, the prevalence rates for women are almost twice those for men and are approximately similar for all ages. The probability of health care seeking for CC is approximately twice for women than for men (36\% versus 20\%). (Level B; vote: a 50\%, b 40\%, c 10\%).

A Canadian population-based study (40) in 1149 subjects reported rates of $27 \%$ when self-reported, $16.7 \%$ when based on Rome I criteria and 14.9\% when based on Rome II criteria. Both Rome definitions of CC require at least two symptoms to be present (from a list of four and six criteria in Rome I and Rome II, respectively). When based on the presence of two or more symptoms, the average rate of CC in this Canadian survey was $16 \%$. Various North American population-based studies (41-43) performed between 1993 and 1997, using the Rome I definition of CC, reported rates varying between $3.6 \%$ and $19.9 \%$. Estimates of Rome II-defined rates of CC in two of these studies (adding outlet symptoms to Rome I rates) were 9.2\% (41) and 30.9\% (43). A systematic review of North American literature (44) also identified variable rates of CC for self-reported definitions.

The Canadian study and all other North American studies, however, showed that for all definitions, the prevalence rates for women are almost twice those for men and are approximately similar for patients in all age groups up to 65 to 70 years. The probability of health care seeking for $\mathrm{CC}$ in the Canadian survey was approximately twice for women than for men (36\% versus 20\%), was stable across all ages for female subjects and increased with age for male subjects (40).

Statement 2: The estimated population prevalence of IBS in Canada is $12.4 \%$ (based on Rome II criteria), of which $45 \%$ report the constipation-predominant subtype (5.4\%). The prevalence rate in women is double the rate in men. (Level B; vote: a 80\%, b 20\%).

According to a Canadian population-based study (45), the estimated prevalence of IBS is $12.4 \%$ (based on Rome II criteria) and the prevalence of IBS-C is $5.4 \%$. For both definitions (IBS and IBS-C), the rate in female subjects is approximately double the rate in male subjects (for IBS-C, $7.5 \%$ versus $3.2 \%$, respectively). Two North American population-based studies $(43,46)$ showed similar rates for IBS-C $(5.2 \%$ using the Manning criteria and 5.5\% using the Rome I criteria). A third North American study (47) reported lower rates for IBS-C of $1.5 \%$ based on Manning criteria and $1.1 \%$ based on Rome II criteria. Female to male ratios were also two to one in both studies that looked at the prevalence according to sex $(43,46)$.

\section{QUALITY OF LIFE AND THRESHOLD FOR THERAPY}

Statement 3: Based on a generic instrument (SF-36), subjects with CC have a significantly decreased quality of life compared with the normal Canadian population or with subjects with no functional constipation. Predictors of poor health-related quality of life are health care seeking, older age or being disabled. (Level B; vote: a $70 \%, b 30 \%)$.
Statement 4: The threshold to treat patients with CC should be based on the patient's assessment of their symptoms and on the impact of these symptoms on quality of life. (Level E; vote: a 70\%, b 30\%).

The existing evidence according to a review of 10 patientbased studies (six in the elderly and three in the severely constipated) suggests that the quality of life is lower in constipated patients than in nonconstipated individuals (48). Based on a generic instrument (SF-36), subjects with CC have a significantly decreased quality of life compared with the normal Canadian population or with subjects with no functional constipation (49). When compared with Canadian subjects without a functional gastrointestinal (GI) disorder, the difference in SF-36 mental and physical subscores in subjects with constipation is greater than five points, a difference considered clinically significant and socially relevant by the creators of the SF-36 assessment tool (50).

In this Canadian population-based survey (49), predictors of poor health-related quality of life, defined as an SF-36 physical component score of less than 45, were disability $(\mathrm{OR}=19.2)$, older age (older than 64 years versus 18 to 34 years, $\mathrm{OR}=8.1$ ), history of physician visit for constipation $(\mathrm{OR}=2.5)$, education (less versus more than high school, $\mathrm{OR}=1.9)$ and sex (female versus male, $\mathrm{OR}=1.6)(\mathrm{P} \leq 0.006$ for all factors). Compared with Canadian data for other chronic diseases, the SF-36 mental component subscore assessed in subjects with CC (49) is lower than in patients with coronary artery disease $(48,51)$, and is in the same range for patients with asthma (52), rheumatoid arthritis or psoriatic arthritis (53). The physical component score for subjects with CC is similar to the one for patients with coronary artery disease or asthma and higher than the one for patients with arthritis. There is an overall positive but weak to moderate correlation between symptom severity and quality of life in CC, especially when symptom severity is assessed using a global score rather than individual symptoms (54-56).

Statement 5: Quality of life is diminished in population-identified subjects with IBS compared with subjects with no IBS. Impairment of quality of life is more severe in patients seeking medical help than in those not consulting. (Level B; vote: a 60\%, b 30\%, c 10\%).

Statement 6: Symptom severity in IBS is a significant predictor of quality of life. (Level B; vote: a 100\%).

Statement 7: The threshold to treat patients with IBS-C should be based on patients' assessment of their symptoms and on the impact of those symptoms on quality of life. (Level E; vote: a 70\%, b 30\%).

Two Canadian population-based studies $(49,57)$ assessed health-related quality of life in IBS subjects using the SF-12 (57) or the SF-36 (49) instruments. Both studies showed statistically decreased mental and physical subscores in IBS subjects compared with those without IBS and with Canadian norms. There was a five-point minimum difference between the groups, which was suggested to be clinically important. IBS consulters also showed a statistical difference of five points when compared with IBS nonconsulters (57). In a study by Irvine et al (49), 54 IBS-C patients showed a five-point difference when compared with non-IBS-C subjects and with Canadian norms.

One large American population-based study (47) in 5009 subjects showed a more frequent impact on well-being and health 


\section{TABLE 3}

Rome III criteria* for functional constipation and constipation associated with irritable bowel syndrome (IBS-C)

Functional constipation
1. Must include two or more of the following:
a. Straining often ${ }^{\dagger}$ during defecation
b. Lumpy or hard stools present often ${ }^{\dagger}$ during defecation
c. Sensation of incomplete evacuation often ${ }^{\dagger}$ during defecation
d. Sensation of anorectal obstruction or blockage often ${ }^{\dagger}$ during defecation
e. Manual manoeuvres needed often ${ }^{\dagger}$ to facilitate defecations (eg, digital
f. Fevacuation, support of the pelvic floor)

2. Loose stools are rarely present without the use of laxatives

3. There are insufficient criteria for IBS

IBS-C

Recurrent abdominal pain or discomfort for three or more days per month in the past three months with two or more of the following:

a. Improvement with defecation

b. Onset associated with a change in frequency of stool

c. Onset associated with a change in form (appearance) of stool

AND hard or lumpy stools present more frequently than $25 \%$ of defecations AND loose (mushy) or watery stools present on occasion $\ddagger$ during bowel movements

${ }^{*}$ Criteria fulfilled for the last three months with symptom onset at least six months before diagnosis. 'Signifies an occurrence of at least $25 \%$ of defecations. ¥Signifies an occurrence of less than $25 \%$ of defecations. Data from references 72,73

in IBS-defined subjects versus control subjects and in IBSdiagnosed patients versus undiagnosed IBS subjects. Several patient-based studies showed a significant reduction in healthrelated quality of life in IBS patients compared with healthy control subjects or population norms $(58,59)$. A patient-based study from a tertiary care centre in the United States reported that the quality of life, as measured by the SF-36 tool, is diminished to the same degree in IBS-C patients as in patients with diarrhea-predominant IBS (IBS-D) and in those with IBS with mixed bowel patterns (IBS-M) (60).

Several patient-based studies showed that IBS patients have worse or similar health-related quality of life scores than do patients with chronic diseases such as gastroesophageal reflux disease, asthma, migraine, diabetes and end-stage renal disease. However, patients with IBS are shown to have better health-related quality of life scores than are patients with chronic diseases such as depression, panic disorder and rheumatoid arthritis $(58,61,62)$. According to four patientbased studies (one Canadian study and three American studies [59,63-65]), data limited to IBS and not specific to IBS-C show that symptom severity (abdominal pain or discomfort and global severity rather than IBS subtypes) is a significant predictor of diminished quality of life.

\section{DEFINITION AND DIAGNOSTIC CRITERIA}

Statement 8: The definition of CC (at least six months duration) or functional constipation is symptom based, including a combination of fewer than three stools per week, stool form that is mostly hard or lumpy, and difficult stool passage (need to strain or incomplete evacuation). Alarm symptoms should not be present. (Level B; vote: a 40\%, b 60\%).

\section{TABLE 4}

Common symptom descriptions used by patients with constipation

Infrequent stools

Hard stools

Difficulty passing stool

Symptoms necessitating the use of laxatives

Incomplete bowel movements

Anal or rectal blockage

Bloating or distension

Most patients with CC have either functional constipation or IBS-C and have macroscopically normal intestinal morphology. Most patients are managed with minimal or no investigations (66). A third group, those with pelvic floor dyssynergia (or outlet obstruction) (67), represents a small subgroup of primary care patients who are often refractory to treatment and do require investigation and treatment in a tertiary referral centre (68).

For most patients, the diagnosis of CC is symptom based, defined by infrequent stools (fewer than three per week) (69), disordered defecation or both $(70,71)$. International experts, the Rome Working Parties, have developed consensus criteria for these disorders, primarily for use in research, to better elucidate the pathophysiology of the disorders and optimize clinical trials methods. The recently published Rome III criteria (Table 3) stipulate that symptom onset be at least six months prior with ongoing symptoms for the past three months $(72,73)$. Most patients seek medical care when they are anxious, experience severe or multiple symptoms, or have substantial comorbidity.

Constipation has been defined by patient self-report, physician diagnosis or using Rome survey criteria. Patient self-report tends to yield the highest frequencies of constipation. The populations, definitions and frequencies of constipation vary considerably (44). Women seem to be at higher risk of constipation and health care seeking for constipation in virtually all studies. The most important thing physicians should clarify is what the patient means by constipation. Straining, hard stools and bloating were reported as the three most prevalent symptoms by Canadian primary care patients being seen for constipation, and were present in $46.8 \%$ of patients who met the criteria for IBS. Straining, hard stools or 'blockage' were reported by $37.3 \%$ of patients with functional constipation (FC) (74). However, $16 \%$ of patients being seen for constipation did not fulfill IBS or FC criteria. Very few patients in the background population ( $4 \%$ of men, $6 \%$ of women) reported needing manual pressure to assist defecation (40). Randomly selected Swedish people interpreted constipation as a need for laxatives (57\%), hard stools (44\%), straining (24\%), pain during defecation (22\%) and infrequent bowel movements (41\% of women, $21 \%$ of men) (75). Table 4 lists common symptoms of patients presenting with constipation.

Statement 9: The definition of IBS-C is symptom based (at least six months' duration), including abdominal pain or discomfort associated with abnormal stool frequency or form fewer than three stools per week, stool form that is mostly hard or lumpy, and difficult stool passage (need to strain or incomplete evacuation). Alarm symptoms should not be present. (Level B; vote: a 70\%, b 30\%). 


\section{TABLE 5}

\section{Secondary causes of constipation}

Organic rectocolonic diseases
Rectocele
Colorectal cancer
Strictures (postdiverticulitis, postischemic, postsurgical anastomosis)
Metabolic conditions
Hypercalcemia
Hypothyroidism (severe)
Diabetes mellitus (with autonomic neuropathy)
Hypokalemia
Chronic renal failure
Diseases of central nervous system
Parkinson's disease
Spinal cord injury
Multiple sclerosis
Enteric myopathies or neuropathies
Sclerodermia
Chronic pseudo-obstruction
Amyloidosis
Miscellaneous
Debilitating psychiatric diseases
Drugs

Recent studies have noted that patients with IBS may switch subcategories of IBS over time and can move between IBS-C and IBS-M (having both constipation and diarrhea over a few weeks) (76). Patients with IBS-C are significantly more likely to report irregular bowel habits, bloating and incomplete evacuation as their primary complaints than are those with diarrhea or IBS-M (60). Therefore, it seems reasonable to ask patients what they mean by constipation and elicit symptoms directly from the list specified in Table 3. Some patients with CC (15\%) will not meet the IBS-C or FC criteria listed.

Potential secondary causes of CC to consider include endocrine causes (eg, diabetes or hyperparathyroidism), neurological disorders (eg, spinal cord injury or Parkinsonism), and the use of narcotics for a chronic pain disorder or organic disease (eg, colon cancer) (Table 5). A careful history will reveal what the patient means by constipation and medication use (narcotics, antidepressants and over-the-counter remedies, including vitamins and other supplements) (Table 6). A physical examination, including a digital rectal assessment, is helpful when investigating for secondary causes.

\section{INVESTIGATION}

Statement 10: Testing to rule out organic disease should be left to the judgment of the treating physician based on symptom severity, the impact on the patient's quality of life, and the presence of risk factors or alarm features obtained from the history and physical examination. (Level E; vote: a 80\%, b 20\%).

Past studies and expert opinion have led to the identification of alarm features or 'red flags' that can assist in discerning subjects with potential organic disease who require judicious investigation. These red flags, listed in Table 7 , are not specific to patients with constipation or other functional disorders and were initially based on expert opinion and observational data $(77,78)$.
TABLE 6

Medications associated with constipation

Opiates

Anticholinergics

Tricyclic antidepressants

Calcium channel blockers

Antipsychotics

Antacids (calcium- and aluminum-based)

Iron supplements

Antidiarrhea drugs

TABLE 7

Red flags that suggest the need for investigation

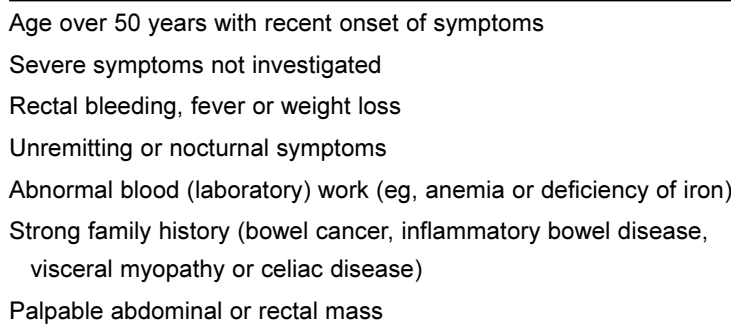

Vanner et al (79) examined the predictive value of one or more Rome criteria for IBS and no red flags in two consecutive groups of referred patients with presumed IBS (retrospectively in 98 patients and prospectively in 95 patients). They observed a sensitivity of $65 \%$, specificity of $100 \%$, positive predictive value (PPV) of $100 \%$ and negative predictive value of $76 \%$ against physician diagnosis and two-year follow-up. Investigations guided by physicians in the prospective series gave a PPV of $98 \%$.

Hammer et al (80) conducted a prospective study of consecutive referrals to a single gastroenterology practice. A careful history and physical examination were performed on all patients. Testing included blood work, ultrasound, endoscopy, barium radiography, measures of gut transit or breath testing, and the choice of test was left to the discretion of the physician based on the clinical presentation. 'Blood on the toilet paper' and 'age over 50 years' discriminated lower GI organic disease from IBS, with ORs of 2.96 and 2.19, respectively, while diarrhea yielded an OR of 2.69 for organic disease (81). Importantly, the greater the number of IBS criteria present (in the absence of alarm symptoms), the greater the PPV for IBS. However, almost one-half of organic conditions would have been overlooked. Given that this study population had relatively few cancer patients, one can conclude that alarm symptoms alone are insufficient to identify patients requiring investigation to rule out organic disease.

Blood work has generally not been found to be useful in assessing patients with CC. A recent systematic overview (81) noted that no studies have assessed routine blood tests or abdominal $\mathrm{x}$-rays in patients with constipation. The prevalence of positive findings by colonic imaging (ileocolonoscopy, flexible sigmoidoscopy or barium enema) was similar between groups with constipation and organic lower intestinal disease. Selection biases and flaws in methodology were evident in all studies examining physiological testing. The authors concluded 
that the treating physician should judge the need for testing based on symptom severity, impact on quality of life, and presence of risk factors or alarm features.

One possible approach to assessing patients awaiting a specialist referral is to offer a standard health biochemical panel (including a complete blood count, calcium, albumin and thyroid-stimulating hormone) and to consider additional testing based on these results, together with other risk factors for GI conditions. Physicians should also follow guidelines for colorectal cancer screening based on age and family history of colorectal cancer (82).

\section{LIFESTYLE CHANGES}

Note: Lactose intolerance was not reviewed because it is primarily a contributing factor in IBS-D patients.

Statement 11: There is insufficient evidence to support the use of additional fluid intake to improve CC. (Level D; vote: a $80 \%$, b 20\%).

The effect of fluid intake on CC has been controversial. A recent review (83) concluded that there was little evidence to support the notion that increased fluid intake had any benefit in treating CC. It is known that stool consistency changes depending on the content of water in the stool (84), and that in Parkinson disease (85) and the elderly (86), fluid intake is inversely related to the severity of CC. However, in another study (87), where 883 elderly subjects over the age of 70 years were interviewed by telephone, fluid intake failed to show any correlation with CC. An Italian study (88) showed improvement in patients with CC who consumed $2 \mathrm{~L}$ of fluid daily compared with the control group who drank fluid as desired. The group drinking the $2 \mathrm{~L}$ per day showed improvement in stool consistency. However, because the fluid used was mineral water with magnesium, it has been argued that the improvement was a result of the laxative effect of the magnesium in the mineral water (83).

In contrast, four other studies (89-92) failed to show that fluid intake had any effect on CC. Only one of these studies (91) had the subjects drinking 2 L or more of fluid daily. Subjects in these studies were not ingesting a large amount of fibre (14.7 g to $18.2 \mathrm{~g}$ of fibre daily), which may have been a contributing factor to the lack of effect seen with fluid intake (see 'Fibre' below).

Further evidence suggests that the amount of fluid ingested may not be important either because healthy subjects drinking up to $2 \mathrm{~L}$ of hypotonic or isotonic fluid daily showed no change in stool output (93). However, in another study of healthy male subjects (94), decreasing fluid intake randomly from $2.5 \mathrm{~L}$ daily to $500 \mathrm{~mL}$ daily for one week reduced weekly stool frequency and stool weight. This study supports the finding that low fluid intake is associated with fewer bowel movements.

Conflicting results were found in two studies $(95,96)$ on the effect of tea on CC. One study (95) found that black tea resulted in softer stools but did not increase frequency. The second study (96) on Chinese tea found an increased incidence of CC with increased intake of Chinese tea along with a decreased intake of rice.

In summary, there are studies that found that increased fluid intake may be important in reducing CC. Increased fluid intake may be more important in a situation where the patient may be dehydrated or drinking very little fluid $(500 \mathrm{~mL}$ per day or less). Whether fluid is required to improve the effect of fibre on CC is also unclear, but a small study (97) of 11 healthy subjects showed little change in orocecal transit or stool frequency with a fibre intake of $30 \mathrm{~g}$ of bran fibre ( $15 \mathrm{~g}$ twice daily) and adding, at random, $600 \mathrm{~mL}$ of extra fluid daily (basal fluid intake of $1000 \mathrm{~mL} /$ day to $1200 \mathrm{~mL} /$ day). The amount of extra fluid required is unclear, but even a daily intake of $2 \mathrm{~L}$ did not consistently change stool output in normal individuals. Chronically constipated individuals may derive more benefit than subjects without CC, but there are no conclusive studies to date investigating this (see discussion below on dietary fibre). The data at present do not support recommending increased fluid intake for CC.

Statement 12: Dietary fibre increases stool weight and shortens gut transit time. (Level D; vote: a 60\%, b 40\%).

The diets of patients with CC compared with control subjects do not differ in the amount of fibre in their diets (89). Fibre does increase stool weight and shortens gut transit time (98) but does not improve symptoms, either pain or stool frequency (99). One study (100) that followed patients with IBS for six months did find that fibre improved the symptoms of CC (hard stools and urgency) but only if the patients ingested $30 \mathrm{~g}$ of fibre or more daily. Abdominal distension, flatulence and diarrhea did not respond to the increased fibre diet (100). A recent review (101) concluded that fibre improves symptoms in CC but studies to date do not clearly identify a particular source of fibre that works best for constipated patients.

At present, fibre can be recommended for the symptoms of CC. However, some associated symptoms of CC and IBS-C, such as pain and abdominal distension, may not be helped by increased dietary fibre $(101,102)$. The amount of dietary fibre may be important; one study (100) found that dietary fibre only had an effect in patients who were ingesting $30 \mathrm{~g}$ of fibre or more a day. There may also be a benefit for high-fibre diets when fluid intake is increased as well (see section above). To date, studies have not explored whether there is an improvement in CC with both increased dietary fibre and increased fluid intake.

Statement 13: There is insufficient evidence to recommend exercise to improve CC. (Level D; vote: a 80\%, b 20\%).

Exercise has been shown to help some individuals with CC (103), but the results have been variable and likely depend on the group studied and the intensity of the exercise performed (104). A large study (105) of over 1000 employees in a Veterans Administration Health Care System used a questionnaire to identify individuals with $\mathrm{CC}$, and they could not find evidence of any difference in exercise in the patients with CC and their coworkers. In healthy subjects, usually men, there has been no consistent change in bowel transit time with moderate exercise (106-108). In a small group of chronically constipated patients $(n=8)$ who did an extra hour of exercise five days per week, there was no improvement in their constipation indices (109). Vigorous exercise does increase bowel function in healthy subjects (110) and the colonic effects of exercise increase as the intensity of the exercise increases (111). Exercise may have more of an effect in the elderly, as shown in a study by Donald et al (112), where CC was associated with poor mobility in 201 elderly patients living at home. Another study showed an increasing likelihood of CC in elderly patients depending on their level of activity, ranging from 
those who walked less than $0.5 \mathrm{~km}$ daily to those who were bedbound (113).

In conclusion, exercise only offers symptomatic improvement in CC to the elderly. Younger patients appear to have little improvement in bowel function unless they engage in vigorous exercise. Exercise can still be recommended to patients because it improves quality of life and has other health benefits unrelated to CC.

\section{BULK-FORMING AGENTS AND STOOL SOFTENERS}

Statement 14: Psyllium is effective in the short-term treatment of CC. Studies of longer duration are lacking. (Level B; vote: a 80\%, b 20\%).

The most commonly used bulk-forming agent in Canada is psyllium powder, which is obtained from the outer coat of the psyllium seed (known in India as ispaghula) from the plant Plantago ovata. In constipated patients, psyllium was more effective than placebo (114-116) or docusate (117) at increasing stool output. Constipation symptoms (eg, abdominal pain, defecation effort, painful defecation and evacuation completeness) were also improved by psyllium. None of these studies lasted for longer than eight weeks; however, clinical experience suggests that the therapeutic effect of psyllium can be maintained for a long time.

Statement 15: Psyllium improves global symptoms in IBS patients. (Level C; vote: a 30\%, b 60\%, c 10\%).

The efficacy of psyllium in IBS was tested in seven randomized controlled trials (RCTs). However, it is impossible to draw firm and specific conclusions for the use of psyllium in IBS-C patients because at the time these studies were performed, patients were rarely characterized for bowel habits. Five RCTs comprising a total of 468 patients supported the therapeutic efficacy of the bulk-forming agent for the treatment of IBS symptoms (118-122). Two studies gave negative results. Longstreth et al (123) did not find psyllium to be better than placebo, although the placebo effect reached $77 \%$ in this study, a factor that could have masked the therapeutic benefit of the bulking agent. A study by Arthurs and Fielding (124) tested psyllium against a placebo in 78 IBS patients. Both patient groups, however, also received a high-fibre diet at the start of the trial that obviously introduced a confounding variable in the results. Psyllium may have a beneficial effect on stool output, but RCTs are needed to confirm this effect. None of the studies on IBS was extended beyond 12 weeks.

Experience with other bulk-forming agents, such as methylcellulose or calcium polycarbophil, has been reported in small trials $(125,126)$, but these results were not conclusive.

Statement 16: There is insufficient evidence to recommend docusate to treat CC. (Level C; vote: a 60\%, b 40\%).

Docusate sodium or calcium salts are widely used for the treatment of constipation. However, the evidence for their therapeutic action is weak. One small trial (127) in 15 geriatric patients suggested that it was better than placebo at increasing stool output. This could not be reproduced by two studies $(128,129)$ in 69 constipated patients or in healthy subjects (130). In one study (117) with a larger population of patients $(n=170)$, docusate was found to be less effective than psyllium in improving constipation. No data were found for the effect of docusate in IBS. Although docusate is considered a safe medication, concerns were raised regarding occasional hepatotoxicity (128).

Statement 17: There is insufficient evidence for the use of mineral or paraffin oil to treat CC in adults. (Level C; vote: a 80\%, b 20\%).

No data were found in the literature on the use of mineral or paraffin oil in adults. Poor palatability and tolerance (anal leakage), as well as fear of side effects, are probably responsible for the limited use of these oils in the treatment of adult constipation. Side effects such as intestinal granuloma formation following oil ingestion, liposoluble vitamin malabsorption or carcinogenicity do not seem of significant concern (131). Mineral or paraffin oil should not be prescribed to patients with swallowing disorders or altered consciousness that could lead to oil aspiration and lipoid pneumonia.

\section{OSMOTIC AGENTS}

Statement 18: There is some evidence that milk of magnesia can be used for CC in patients with normal renal function. (Level C; vote: a $80 \%$, , $10 \%$, c 10\%).

Despite a lack of evidence from RCTs, milk of magnesia (magnesium hydroxide $[\mathrm{MgOH}]$ ) has shown efficacy when used chronically for mild to moderate CC. Expert opinion, based on clinical experience in patients with constipation, is that this agent may be effective in IBS-C patients whose pain is markedly improved after a bowel movement. Because of the risk of hypermagnesemia, it should not be used in patients with renal impairment.

Only one RCT (132) of 64 institutionalized patients with CC compared a $20 \mathrm{~mL}$ daily intake of $\mathrm{MgOH}$ to a combination agent containing a bulk laxative plus sorbitol. Patients in the $\mathrm{MgOH}$ group had significantly more bowel movements and more normal stool consistency. There are no controlled clinical trials of $\mathrm{MgOH}$ in IBS-C patients. There is a need for RCTs on $\mathrm{MgOH}$ in CC and IBS-C. There are no RCT data for other agents containing magnesium and thus, no recommendations can be made for their use in clinical practice.

Statement 19: Daily polyethylene glycol (PEG) is effective at treating CC for eight to 24 weeks by normalizing bowel frequency and improving stool consistency. (Level A; vote: a 100\%).

Statement 20: Daily PEG facilitates discontinuing other laxatives. (Level B; vote: a 60\%, b 30\%, c 10\%).

Daily doses of PEG, an agent usually used as part of the preparation for procedures such as colonoscopy, are effective at treating CC, normalizing the frequency of bowel movements, decreasing straining and improving stool consistency. In addition, daily PEG facilitates discontinuing other laxatives. Daily use of PEG is safe and does not have significant side effects. A reasonable starting dose of PEG is one to two glasses per day (eg, $250 \mathrm{~mL}$ to $500 \mathrm{~mL}$ of a PEG agent).

A total of nine controlled trials (133-141) in over 500 patients have yielded some conclusive results. Six of these studies explicitly described patients as chronically constipated, while two mentioned a history of constipation. First, daily use of PEG is effective at treating CC, normalizing bowel frequency (number needed to treat $[\mathrm{NNT}]=2.4$ ) and improving stool consistency (NNT=3 to 4). Second, a daily intake of PEG facilitates stopping the use of other laxatives $(\mathrm{NNT}=3.1)$ and decreases straining $(\mathrm{NNT}=3.2) \quad(135)$. Third, three RCTs $(135,137,142)$ of eight to 24 weeks' duration in 240 patients 
have shown that daily PEG intake is safe, does not have significant side effects and is effective for up to six months.

Other randomized studies have shown that PEG is effective at treating Rome II CC overnight (NNT=2.6) (141) and opioidinduced constipation (136). Another open-label study (138) showed normalization of colonic transit in patients with documented chronic ST constipation. An RCT (137) of 115 patients with CC compared PEG with lactulose and found that PEG was significantly better than lactulose at improving stool frequency, straining, need for rescue medications and side effects, and also showed a better patient-rated overall improvement. Further long-term studies (six to 12 months or longer) to assess the efficacy and safety of PEG are needed.

Statement 21: There is insufficient evidence to base recommendations for the role of PEG or lactulose in IBS-C. (Level D; vote: a $80 \%, b 20 \%$ ).

Expert opinion on the use of PEG in IBS-C based on clinical experience in patients with constipation is that this agent may be effective in patients whose pain is markedly improved after a bowel movement. If the patient responds, this agent should be safe and effective. There is a need for studies of this agent in IBS-C because there are no controlled clinical trials of PEG in this patient population.

Statement 22: Lactulose improves bowel movement frequency and stool consistency. (Level B; vote: a 100\%).

Lactulose is effective at normalizing the frequency of bowel movements and probably also improves stool consistency (a suggested starting dose is $15 \mathrm{~mL}$ to $30 \mathrm{~mL}$ orally once a day, with dose changes based on patient response).

Two RCTs $(143,144)$ in patients with CC (totalling over 150 patients) and a further RCT (136) of 57 patients with opiateassociated constipation (duration not specified) have shown that taking lactulose results in the normalization of bowel movement frequency (NNT=3.9) and significant improvement in stool consistency and frequency in patients on chronic opiates (see section on PEG for a study comparing the two agents).

An RCT (145) of 124 patients with at least three weeks of idiopathic constipation compared lactulose to psyllium (ispaghula) and showed that both agents were equally effective at increasing the number of bowel movements, improving stool consistency and global symptoms, decreasing abdominal pain and decreasing straining. However, patients found psyllium significantly less palatable than lactulose (number needed to harm $[\mathrm{NNH}]=7.8)$. Because only one of the studies mentioned above (143; 55 subjects) lasted 12 weeks (the rest were two to four weeks), evidence about the long-term use of this agent is limited. Further studies of this agent with a duration of six to 12 months or longer are needed.

Expert opinion on the use of lactulose in IBS-C (based on clinical experience in patients with constipation) is that this agent may be effective in patients whose pain is markedly improved after a bowel movement. In light of the side effect profile of lactulose in RCTs of patients with CC, it should probably be tried after PEG in IBS-C. There is a need for studies of this agent in IBS-C because there are no controlled clinical trials in this patient population.

\section{PROKINETICS}

Statement 23: There is insufficient evidence to support the use of erythromycin or domperidone in CC and IBS-C. (Level D; vote: a $90 \%, b 10 \%)$.
Erythromycin has been proposed as a therapeutic agent for the treatment of functional motor disorders of the upper GI tract. Some data exist showing a potential effect on colonic motility, but there is currently insufficient evidence to support the use of erythromycin to treat CC and IBS-C. Domperidone is a dopamine receptor antagonist. Currently, there is insufficient evidence to support the use of domperidone to treat CC and IBS-C. There are three small studies (146-148) on the use of domperidone to treat symptoms of IBS but nothing specific to constipation.

Statement 24: There is evidence for the short-term (three months) use of tegaserod in CC in women. (Level A; vote: a 80\%, b 20\%).

Tegaserod (see 'Important Note' at the end of the paper) is effective in treating patients with CC and patients with IBS-C. In Canada, it is approved for chronic use. There is evidence to support the use of tegaserod for the short-term treatment of CC. Data have been presented (149) to also support the long-term use of tegaserod for CC. Data from a 13-month study (149) in CC patients who responded to tegaserod $6 \mathrm{mg}$ twice daily after a fourweek period revealed that tegaserod confers long-term improvement in multiple symptoms of CC. In this blinded extension study, 113 of 278 patients on $6 \mathrm{mg}$ twice daily of tegaserod were four-week responders. Of the $113,88 \%$ were responders at the end of 12 weeks and 91 of 107 (85\%) were responders at the end of the 13 months (149). A 13-month study by Muller-Lissner et al (150) of 451 patients also demonstrated the long-term safety profile of tegaserod and showed that it is well tolerated.

Studies show that tegaserod is effective in the relief of constipation. A study by Kamm et al (151) of 1264 patients showed that the responder rates for the primary efficacy variable were $40.2 \%$ for tegaserod $6 \mathrm{mg}$ twice daily and $26.7 \%$ for placebo $(\mathrm{P}<0.0001$ versus placebo). The NNT was seven for the $6 \mathrm{mg}$ twice daily dose (95\% CI 0.78 to 0.92). Tegaserod $6 \mathrm{mg}$ twice daily reduced straining, abdominal bloating and distension, and abdominal pain and discomfort during the 12-week treatment period compared with placebo $(\mathrm{P}<0.05$ for all symptoms). Significant improvements were also seen in stool form and in global assessment of bowel habits and constipation. A study by Johanson et al (152) of 1350 patients showed that responder rates for complete spontaneous bowel movement during weeks 1 to 4 were significantly greater in the tegaserod $6 \mathrm{mg}$ twice daily groups $(43.2 \%)$ versus placebo (25.1\%). In the study, this effect was maintained over 12 weeks.

Both RCTs by Kamm et al (151) and Johanson et al (152) evaluated the efficacy of tegaserod $2 \mathrm{mg}$ twice daily and $6 \mathrm{mg}$ twice daily versus placebo in patients with constipation. The two doses of tegaserod did not show a statistically significant difference in improving constipation; thus, the results for both were combined. Both trials predominantly evaluated women (90\% and $86 \%$, respectively). The trials evaluated 2612 patients with constipation over 12 weeks. A statistically significant benefit of tegaserod over placebo was shown $(\mathrm{RR}=0.81 ; 95 \% \mathrm{CI}$ 0.74 to 0.89 ), with an NNT of seven (95\% CI 5 to 12.5 ) (153).

Statement 25: There is evidence for the short-term (three months) use of tegaserod in IBS-C in women. (Level A; vote: a 90\%, b 10\%).

Current evidence supports the short-term (three months) use of tegaserod (see 'Important Note' at the end of the paper) to treat IBS-C. Published data from an open-label study (154) also support the long-term use of tegaserod for IBS-C (154). Tegaserod has been shown to improve bloating, straining, and stool frequency and consistency. In a fourweek, double-blind, placebo-controlled study, 2660 patients 
were entered into an initial four-week phase (155). Of the patients entered into the treatment phase, 1191 were responder patients who were retreated (ie, had a repeat treatment four weeks later). Tegaserod was shown to be superior to placebo in each treatment phase. In the first phase of treatment, $33.7 \%$ of tegaserod patients experienced relief from IBS symptoms compared with $24.2 \%$ of patients on placebo. Among the 1191 patients who were retreated in the second phase of treatment, $44.9 \%$ of tegaserod patients experienced relief of IBS symptoms compared with $28.7 \%$ of patients on placebo. A 12 -week study (156) of 1519 women with IBS-C showed that tegaserod, $6 \mathrm{mg}$ twice daily, produced significant improvements in the subject's Global Assessment of Relief $(\mathrm{P}<0.05)$.

A 12-week study of 881 patients with IBS-C showed that those treated with tegaserod $6 \mathrm{mg}$ twice daily experienced statistically significant relief of overall IBS symptoms (157). At end point, the treatment difference compared with placebo was $11.8 \%$ for tegaserod $6 \mathrm{mg}$ twice daily. There was also a statistically significant improvement of abdominal discomfort and pain, number of bowel movements and stool consistency, and a favourable trend for reducing days with significant bloating with tegaserod. Another study (158) randomly assigned 166 patients to receive tegaserod $6 \mathrm{mg}$ twice daily for 12 weeks. These subjects were assessed for response, abdominal pain and discomfort, bloating, stool consistency and frequency, and straining at four and 12 weeks. Response rates were $64.2 \%$ at week 4 and $70.3 \%$ at week 12 . After 12 weeks, abdominal pain and discomfort and bloating were reduced from baseline $(\mathrm{P}<0.0001)$, stool frequency increased and stool consistency improved.

A Cochrane Review on tegaserod in IBS concluded that tegaserod may be an effective treatment for IBS-C. Patients with IBS-C taking tegaserod reported an increase in number of bowel movements per day and a reduction in the number of days without a bowel movement (159). To revise the Cochrane Review for IBS-C results alone, the studies that did not specifically evaluate IBS-C were excluded and the review was updated by identifying any other IBS-C trials. There was a trend toward tegaserod improving constipation in IBS-C with an RR of improvement in constipation of 0.91 (95\% CI 0.83 to $1.002 ; \mathrm{P}=0.056)$. Although female patients were the majority in studies with tegaserod and data in men are lacking, the drug was believed to be effective in both sexes by the consensus group.

In a 12-month, multicentre, open-label study (154), the long-term safety of tegaserod was determined in 579 IBS-C patients. Of these, 304 patients completed the study. By the end of the safety study, a total of 40 adverse events were reported in 25 patients. The most common were mild and transient diarrhea (10.1\%), headache $(8.3 \%)$, abdominal pain $(7.4 \%)$ and flatulence $(5.5 \%)$. All of these studies of tegaserod in CC and IBS-C showed that the drug is generally safe and well tolerated.

To date, tegaserod has not been compared in head-to-head trials with other agents in patients with CC or with IBS-C.

\section{STIMULANT LAXATIVES}

Statement 26: There is some evidence to support the short-term use of senna or sodium picosulphate in CC. There is no evidence supporting the long-term use of these agents. (Level C; vote: a 70\%, b 30\%).

Stimulant laxatives include senna, cascara, castor oil, bisacodyl and sodium picosulphate. They have remained a popular measure for use in either intermittent constipation or
CC for many decades. The clinical data supporting their use in $\mathrm{CC}$ are derived from small, older and poorly designed studies (160-165). These studies were often done in specific subsets of patient populations and had ill-defined end points (166-171). Concern has been expressed over potential side effects, including electrolyte disturbances, abdominal cramping, nausea and bloating. In addition, reports of tachyphylaxis and dependency have long been considered, although with little supportive evidence. Castor oil should no longer be used. In spite of this lack of evidence, many clinicians and patients find stimulant laxatives useful in the management of acute constipation or CC, or as a critical part of a colon cleansing program in preparation for endoscopic, radiological or surgical procedures.

\section{SUPPOSITORIES}

Statement 27: There is some evidence to support the short-term use of suppositories in CC. (Level C; vote: a 40\%, b 60\%).

Suppositories have been in use for many decades for CC in many forms, including the presumably inert but lubricating glycerin, and as stimulants, such as bisacodyl. In spite of their inclusion in many 'bowel protocols' and the personal testimonials of individuals, there is weak evidence to support their usefulness in the management of CC (172-174).

\section{ENEMAS}

Statement 28: There is insufficient evidence to support the use of enemas in CC. (Level D; vote: a 50\%, b 50\%).

Enemas have been used for hundreds of years in a variety of forms, including water, soapsuds, phosphate and sugar solutions. In spite of this long history, there is only anecdotal evidence for their value in the management of CC $(175,176)$. However, even in the absence of good evidence for their efficacy, many clinicians and patients find them useful and effective both for the treatment of acute constipation or CC and as a means of preparing or cleansing the distal colon for endoscopic or surgical procedures. Phosphate enemas should be used with caution in patients with impaired renal dysfunction, pre-existing electrolyte imbalances, risk of electrolyte disturbance (hypocalcemia, hyperphosphatemia or hypernatremia) or a serious adverse event secondary to one of the above, dehydration, chronic inflammatory bowel disease, gastric bypass or stapling surgery (177). Because of their adverse irritating effect, soapsud enemas should be avoided.

\section{OTHER DRUGS}

Statement 29: There is insufficient evidence that antispasmodics are effective in treating constipation in IBS-C patients. (Level C; vote: a $80 \%, b 20 \%$ ).

There are no data to support the use of antispasmodics in $\mathrm{CC}$, and there is insufficient evidence that antispasmodics are effective in treating constipation in IBS-C patients. There were no studies found on the effects of antispasmodics in CC. A meta-analysis of 23 RCTs (178) identified four studies that examined the effects of antispasmodics in constipation in a total of 230 patients with IBS. The studies concluded that in comparison with placebo, antispasmodics have no effect on constipation. However, antispasmodics did improve the global symptoms of IBS ( $56 \%$ versus $38 \%, \mathrm{OR}=2.13 ; \mathrm{P}<0.001$ ) in comparison with placebo. A Cochrane Review (179) on the use of antispasmodics in IBS suggested that these agents may 
be effective for IBS treatment because they improve abdominal pain and patients' overall assessment of their IBS symptoms with a NNT of five. Antispasmodic agents were shown to be efficacious in relieving pain in IBS in general but not especially in IBS-C. In another meta-analysis (180), smooth muscle relaxants were shown to be beneficial when abdominal pain was the predominant symptom.

Statement 30: There is insufficient evidence to recommend the use of bisacodyl in CC. (Level E; vote: a 80\%, b 20\%).

There were no studies found on the effects of low-colonic bisacodyl suppositories in the treatment of IBS-C. There are anecdotal reports $(181,182)$ on the use of bisacodyl in CC as a bowel preparation and in nursing homes. However, relief of constipation was not measured as a primary outcome.

Statement 31: There is limited evidence to suggest a role for colchicine in the short-term treatment of carefully selected CC patients with informed consent in view of potential toxicity. (Level C; vote: a 50\%, b 50\%).

One RCT (183) performed in disabled patients showed a significant decrease in laxative use in eight of 11 patients treated. This study was followed by an open-label study (184) in CC patients, which showed an increase in the number of bowel movements per week from 1.7 to six after subjects were given colchicine $0.6 \mathrm{mg}$ three times daily $(\mathrm{P}<0.05)$. A four-week RCT (185) showed a decrease in colonic transit time with colchicine, and an increase in the number of bowel movements per week. There are no data to support a role for colchicine in IBS-C.

Statement 32: There is limited evidence for the use of misoprostol in selected patients with CC. It should not be used in women of child-bearing potential. (Level C; vote: a 40\%, b 60\%).

Only one RCT (186) was found on the use of misoprostol for CC. However, the short period of the trial and the number of patients treated $(n=8)$ are substantial limitations to this study. Treatment of patients with CC with misoprostol $1200 \mu \mathrm{g} /$ day induced a decrease in colonic transit time from $109 \mathrm{~h}$ to $66 \mathrm{~h}(\mathrm{P}<0.05)$ and an increase in the number of spontaneous bowel movements per week from 2.5 in the placebo group to 6.5 in the misoprostol-treated patients $(\mathrm{P}<0.01)$. There was no difference in the incidence of abdominal pain among patients in both groups. In another study (187), 18 consecutive patients were treated with misoprostol in an openlabel fashion. Misoprostol, given at a dose of $600 \mu \mathrm{g}$ to $2400 \mu \mathrm{g}$, was associated with a decrease in the number of days between spontaneous bowel movements from 11.8 to 4.8 days $(\mathrm{P}<0.004)$. Six patients withdrew from this study citing severe abdominal cramping as the reason and only 12 patients were evaluated at the end of the study. A cautionary note must be made for the use of misoprostol in women of child-bearing age because the drug could potentially induce an abortion (188).

Statement 33: There is insufficient evidence to support the use of trimebutine in CC. (Level C; vote: a 90\%, b 10\%).

Trimebutine is not efficacious for the treatment of constipation in IBS-C patients. No recommendation can be made for its use in that setting. Four RCTs (189-192) were found that assessed the effects of trimebutine in patients with IBS-C. Trimebutine was not associated with a significant effect in treating constipation in IBS patients. In one study (193), patients with CC were randomly assigned to receive trimebutine $200 \mathrm{mg} /$ day or placebo for four weeks. Trimebutine was associated with a decrease in colonic transit time in patients with delayed colonic transit time, but it had no effect on the colonic transit time of patients with normal colonic transit time. Moreover, trimebutine failed to change stool frequency in treated patients compared with control subjects.

\section{BEHAVIOURAL THERAPY}

The underlying focus of behavioural therapy is to effectively use the patient's own powers to break the negative feedback loop between emotion and gut function in order to reduce symptoms.

\section{Biofeedback}

Statement 34: Biofeedback, a specific variant of behavioural therapy, is an effective treatment for selected patients with CC due to pelvic floor dyssynergia. (Level B; vote: a 70\%, b 30\%).

Biofeedback is a learning strategy based on operant conditioning using electrical or mechanical devices to increase awareness of a biological response (194). In the setting of CC, biofeedback therapy is directed at coordinating pelvic floor relaxation using downward intra-abdominal pressure to enhance the passage of stool into the rectum and facilitate anal relaxation.

A systematic review of studies on the use of biofeedback for pelvic floor dyssynergia shows an overall success rate of approximately 70\%, although there are limited data from controlled trials (195-197). Treatment has been shown to improve symptoms and quality of life, hasten transit time and reduce laxative use $(194,198,199)$. A recent controlled study (200) demonstrated that biofeedback is more effective than laxative use and patient education for chronic outlet dysfunction constipation. Longterm follow-up data from several studies (197,198,200-203) demonstrated a prolonged effect from biofeedback that was maintained for up to two years following therapy.

There are conflicting data regarding the efficacy of biofeedback for ST constipation. Early studies (194,198,201,204-206) showed that patients with ST constipation may benefit from biofeedback therapy. The initial efficacy seen in patients with ST constipation seemed to diminish over the long term. On the other hand, a recent study (4) reported biofeedback to be more effective for treatment of outlet constipation than for ST constipation. The authors concluded that pelvic floor dysfunction was actually the cause of the slow transit, although the mechanism is unknown.

There are several methods of biofeedback, including anal manometry, electromyography (EMG) of the external anal sphincter and puborectalis muscles, and sensory training with evacuation of a water-filled balloon from the rectum (207-209). Comparative studies $(210,211)$ have suggested that pressure techniques may be more effective than EMG. Intra-anal and perianal EMG biofeedback techniques have demonstrated similar efficacy (207). However, training without biofeedback was ineffective (207). Simulated evacuation with a water-filled balloon is often used to reinforce the normal coordination of pelvic floor relaxation and intra-abdominal pressure required for successful defecation $(197,204)$.

The success of biofeedback may be influenced by a number of factors, including the number of biofeedback treatment sessions (212). Physiological variables identified to predict a response to biofeedback include dyssynergia on rectal manometry, inability to defecate a water-filled balloon and rectal stasis (197). 
Patients with more severe constipation with slow transit time and fewer bowel movements did not fare as well on this therapy (197). The ideal patient must be motivated and willing to spend time to alleviate symptoms. In addition to coordination training, biofeedback also involves patient advice and education. Rapport between the patient and the therapist is essential (198). Most studies have a single highly trained physician or technician performing all biofeedback sessions. To date, there is no identified standard for training biofeedback technicians to treat pelvic floor dyssynergia (213).

There are limited data demonstrating biofeedback to be effective in patients with constipation after hysterectomy (214), solitary rectal ulcer (215) and mild neurological disease, such as multiple sclerosis (216). There is very limited evidence regarding the use of other behavioural therapies for the treatment of CC, which was shown to be resistant to hypnotherapy (217) and counselling alone (218).

Behavioural therapy is noninvasive and safe, with central and peripheral effects (194). Although the results of the studies performed to date are difficult to compare, it seems logical and reasonable to offer biofeedback as first-line therapy for CC due to outlet dysfunction. However, there is limited access to this technology in Canada due to a lack of trained personnel and limited availability of instrumentation. The value of behavioural therapy for $\mathrm{CC}$ requires further assessment by careful prospective evaluation of patient symptoms and physiological function. Long-term follow-up for CC patients on biofeedback therapy is required, including an assessment of cost-effectiveness in community practice.

\section{Hypnotherapy and cognitive behavioural therapy}

Statement 35: Various forms of behavioural therapy, including hypnotherapy and cognitive behavioural therapy (CBT), are useful, safe therapies for selected people with IBS-C. (Level B; vote: a 70\%, b 30\%).

Behavioural therapy for IBS is based on the close association between psychological factors and altered gut function in the development and continuation of symptoms in IBS (219). There is increasing evidence, including several recent large RCTs $(217,220)$, demonstrating that various behavioural modalities, such as hypnotherapy, relaxation therapy, interpersonal psychotherapy, and various combinations of cognitive and behavioural therapies, lead to significant improvement in some people with IBS. All have reported success in $60 \%$ to $80 \%$ of patients resistant to medical therapy. The underlying focus of behavioural therapy is to effectively use the patient's own powers to break the negative feedback loop between emotion and gut function to reduce symptoms. Psychological factors associated with IBS are not thought to be causal; rather, they influence gut function through the interaction of the central and enteric nervous systems (221).

\section{Hypnotherapy}

Gut hypnotherapy has been shown to be effective for patients with IBS in several uncontrolled trials (222-224) and RCTs $(217,225)$. Controlled trials $(217,225)$ demonstrated hypnotherapy to be effective in reducing abdominal pain and improving bowel habits. In addition to providing symptom relief of IBS, the therapy was safe and well tolerated. Gut hypnotherapy involves the induction by a therapist of a trance-like state of deep muscular relaxation, rendering the patient susceptible to the suggestions of bowel-directed imagery to alter gut function (217). Gut-directed hypnotherapy involves a course of up to 12 weekly $1 \mathrm{~h}$ sessions that must be provided by highly trained individuals in a safe environment (217). The aim is to assist the patient in gaining control over bowel symptoms. Hypnotherapy should not be performed on patients with serious coexistent psychological illness (217). Several studies $(217,223,224,226)$ have demonstrated persistent improvement in bowel habits and general well-being for up to five years following hypnotherapy. Response rates to hypnotherapy are lower in patients with chronic abdominal pain and no alteration of bowel habits, patients with significant coexistent psychological disease and patients over the age of 50 years (227). Hypnotherapy has also been successfully performed in groups and at home, making it potentially more readily available and cost-effective $(222,228)$.

IBS symptoms are associated with physiological changes, including exaggerated autonomic arousal, enhanced visceral sensitivity and altered colonic motor activity (229). Hypnosisinduced anger and excitement were associated with exaggerated motor activity in the sigmoid and enhanced rectal sensitivity. Hypnotherapy has been demonstrated in a number of studies (229-232) to normalize abnormal visceral sensitivity, alter GI motility and reduce pain. Others did not demonstrate such an effect (233).

Most behavioural studies (234) involving the use of hypnotherapy have methodological problems in that they do not specifically address the use of therapy for subgroups such as IBS-C. The predominant bowel habit of the patient does not appear to affect the response to the various hypnotic states. A study by Prior et al (231) noted that there was improved tolerance to rectal balloon distension in IBS-D but not in IBS-C. Galovski and Blanchard (225) compared hypnotherapy with a symptom-monitoring wait list in six matched pairs with IBS. Hypnotherapy patients had improvement in a composite score of pain, diarrhea, constipation, bloating and flatulence, belching and nausea. Individual symptoms, including pain, constipation and flatulence, showed significant improvement.

\section{CBT}

CBT has been reported to be effective in individual and group treatment of IBS (235-248). Many studies have a controlled design but have other methodological limitations, and the reported positive results are often difficult to differentiate from a placebo response. A variety of psychotherapeutic approaches, including interpersonal psychotherapy, relaxation therapy and various combinations of cognitive and behavioural therapies, have been found to be effective in the treatment of IBS (242). A recent study (247) demonstrated that the benefits of therapy were not mediated solely by a reduction in psychological distress. A supportive physician-patient relationship by itself can be associated with alleviation of patient symptoms. There are a limited number of trials $(249,250)$ comparing the effect of pharmacotherapy and behavioural psychotherapy. Stress-managed patients reported greater confidence regarding their illness. In a study (251) of CBT delivered by nurses, there was additional benefit of CBT over the use of pharmacotherapy with mebeverine alone for up to six months. Numerous studies $(235,242,252,253)$ of multicomponent therapy for IBS have been performed. Boyce et al (246) demonstrated significant improvement in all three treatment groups - standard care versus standard care and relaxation treatment versus standard care and CBT. However, there was no significant difference among 
the three groups. The effect was maintained at one year. This is in contrast to other studies that demonstrated a significant benefit of CBT over standard care $(235,236,239,242,253)$. IBS patients not previously treated may respond differently than those with severe refractory IBS $(217,242)$.

There are limited data regarding the efficacy of CBT for IBS-C. In a large RCT, Drossman et al (220) compared CBT against education and desipramine versus placebo for moderate to severe IBS. CBT consisted of 12 weekly $1 \mathrm{~h}$ sessions with a psychologist focused on modifying the influence of attention, personal appraisal, sex-related cognitive schemas and illness attribution to the GI symptoms as a means to develop more effective coping strategies. CBT was found to be more effective than education for all subgroups except depression. Participants with less severe illness, or no depression, responded better to therapy. Similar benefits for CBT were demonstrated in IBS-C and IBS-D subgroups. There was no difference between the effects of CBT and desipramine. Guthrie et al (218) assessed psychotherapy versus standard medical therapy. Those with diarrhea and abdominal pain were much more responsive than those with constipation. Blanchard et al (235) compared multicomponent therapy (elements of education, relaxation, biofeedback, and cognitive therapy or psychological therapy) versus symptom monitoring. After three months, treated patients had less pain, distension and diarrhea, but not less constipation. Creed et al (254) showed psychotherapy for severe IBS patients to be superior to standard treatment in improving the physical aspects of health-related quality of life. There was no difference between subtypes of IBS on primary outcome.

CBT has been compared to self-help therapies $(237,255)$ and to treatment with the aid of a highly developed guidebook (256). IBS patients treated with self-help therapy or a focused guidebook showed significant benefit, with a decrease in perceived symptom severity. Because not all patients are receptive to psychotherapy, the use of a guidebook may be a practical and potentially cost-effective treatment approach.

CBT, hypnosis, relaxation therapy, dynamic interpersonal therapy, stress management and education may be appropriate therapies in a select group of IBS-C patients $(217,223-226,242,249-251)$. Controlled trials of behavioural intervention for IBS-C are limited, but there is evidence to suggest that CBT and hypnotherapy may be helpful $(217,220,223,224,226)$. Knowledge of a patient's predominant initial symptom complex is important to determine initial therapy, but it is well recognized that patients frequently switch from their baseline subtype. This has potential implications for pharmacological and psychotherapeutic interventions. Effective behavioural therapies for IBS-C and IBS-D may play an important role in the future management of IBS (76). Many physicians practice supportive and relaxation therapy. In Canada, behavioural therapies for IBS-C are not readily available by highly skilled therapists. Advanced behavioural therapies are also time consuming and potentially costly. However, a study (249) demonstrated that CBT for IBS was associated with a significant long-term decrease in health care costs compared with standard care. Further research evaluating behavioural therapies in IBS-C with larger sample sizes would be beneficial. Prospective long-term studies of behavioural psychotherapies and combination therapies are required at the level of the primary care physician to substantiate effectiveness of therapy and test validity.

\section{SURGERY}

Statement 36: Carefully selected patients with ST CC will benefit from total abdominal colectomy and ileorectal anastomosis. (Level D; vote: a 50\%, b 50\%).

Partial or total colectomy has been used to treat CC from early in the 20th century. This radical surgery has generally been performed by means of an ileorectal anastomosis after colectomy. Patient satisfaction rates vary from $39 \%$ to $100 \%$ (250). Surgical intervention should only be contemplated in refractory cases where symptoms are significant, where more conservative measures have clearly failed (251) and after appropriate expert investigation has been performed.

\section{PROBIOTICS}

Statement 37: There is insufficient evidence to support the use of probiotics in the treatment of CC. (Level C; vote: a 60\%, b 40\%).

Although probiotics are becoming popular in the treatment of a spectrum of GI conditions, there is insufficient evidence to recommend their use in CC. Only one RCT (252) was found in which Lactobacillus casei was administered in a beverage. The beverage without probiotic was used as placebo. The study lasted four weeks and involved 70 patients with CC. A self-report of improvement was used to determine efficacy and this was seen in $89 \%$ of probiotic-treated patients compared with $58 \%$ of control subjects. No adverse effects were noted. More severely constipated patients were found in the placebo-treated group. This single, short-term study did not exclude IBS patients.

Statement 38: There is insufficient evidence to support the use of probiotics in the treatment of IBS-C. (Level C; vote: a 80\%, b 20\%).

While there have been five RCTs $(253,255-258)$ on the use of probiotics in IBS, none focused on IBS-C specifically. A study by Niv et al (253) showed no significant benefit of Lactobacillus reuteri in a mixed group of IBS patients treated over six months. Kim et al (257) showed a reduction in flatulence in a mixed group of IBS patients treated over six months with a probiotic mixture (VSL3). Treatment was associated with a decrease in colonic transit time, but there was no effect on stool passage. A study by O'Mahony et al (255) using Bifidobacterium infantis showed a significant improvement in pain and bloating in a mixed IBS population, but there was no effect on the passage of stool. Nobaek et al (256) treated 60 IBS patients for four weeks, and the study showed an improvement in flatulence but no other symptoms. Finally, a study by Niedzielin et al (258) found a global improvement among 40 patients with IBS, and a response was seen in six of 10 constipated patients over four weeks.

This is an emerging field of therapy and our current understanding of the mechanisms of action and potential benefits of probiotic strains is still in its infancy. It is evident that different bacterial strains produce different effects on host physiology and, therefore, results obtained with one probiotic cannot be extrapolated to another. In addition, concerns regarding dosage and the limited standardization of the content of commercially available probiotic preparations further undermine the authors' ability to provide a broad recommendation for the use of probiotics in CC and in IBS-C. Previous studies used mixed IBS populations and were generally of short duration, but it is expected that these shortcomings will be rectified over the course of time and that a 
more precise evaluation of probiotics in this area will be forthcoming.

\section{MANAGEMENT ALGORITHM FOR CC}

An algorithm for the management of CC is shown in Figure 1. It is based on expert opinion and is supported by clinical evidence where available.

\section{Box 1}

The presence of alarm features or red flags must initiate appropriate investigation to rule out organic and secondary causes of CC (Tables 5 and 7). Individuals 50 years and older with no red flags should undergo counselling about colon cancer screening. Medications that can be associated with constipation should be reviewed and, if possible, discontinued (Table 6). Abuse of laxatives can be detected by a history of increases in dose of these medications or having loose stools or urgency. More appropriate therapy in these patients may improve their level of satisfaction with their medication, as well as decrease costs.

The main clinical features of IBS-C are abdominal pain or discomfort, which are the dominant symptoms related to altered bowel habits (Table 3 ). In a patient diagnosed with IBS-C, based on the evidence, dietary fibre improves the constipation component and antispasmodics improve the global symptoms with no effect on constipation. Psyllium supplements and tegaserod (see 'Important Note' at the end of the paper) improve both the constipation and the global symptoms. IBS-C patients should be initially managed with dietary fibre and/or psyllium and, if needed, antispasmodics. Over-the-counter antispasmodics are cheaper than prescription antispasmodics. If response to this initial therapy is inadequate, tegaserod is the preferred treatment. If the patient responds to tegaserod, intermittent or long-term use could be proposed. Tegaserod is not proposed as first-line therapy because of its higher cost, although it is the drug for which evidence of efficacy is the best supported by clinical research. The NNT for tegaserod in IBS-C is 14. Tricyclic antidepressants can be used in selected patients whose abdominal pain remains a resistant symptom, but they may increase constipation.

\section{Box 2}

Self-reported constipation is not sufficient to establish a diagnosis of constipation. Taking a patient's history is a crucial step in reviewing the symptoms of constipation that can be clinically grouped into infrequent stools and difficult defecation. Patients must be educated on the variability of bowel function in normal individuals, stool formation from dietary fibre and the mechanism of normal defecation (initiated by rectal distension, anal relaxation and expulsatory action of pelvic musculature).

\section{Box 3a}

Most patients with CC have normal colonic transit (1); these patients have a good to excellent response to fibre intake (259). Therefore, a gradual increase in fibre, incorporated into the diet (bran) and/or used as supplements (psyllium, methylcellulose or calcium polycarbophyl) should be the initial approach in managing CC. Patients need to be instructed that fibre does not yield an immediate improvement but will increase stool formation. Side effects, such as flatulence and bloating, can be controlled by a slow but gradual increase in the amount of fibre taken. Therapy should be maintained long-term even if the addition of laxatives is needed. There is no evidence that increasing water intake improves the effect of

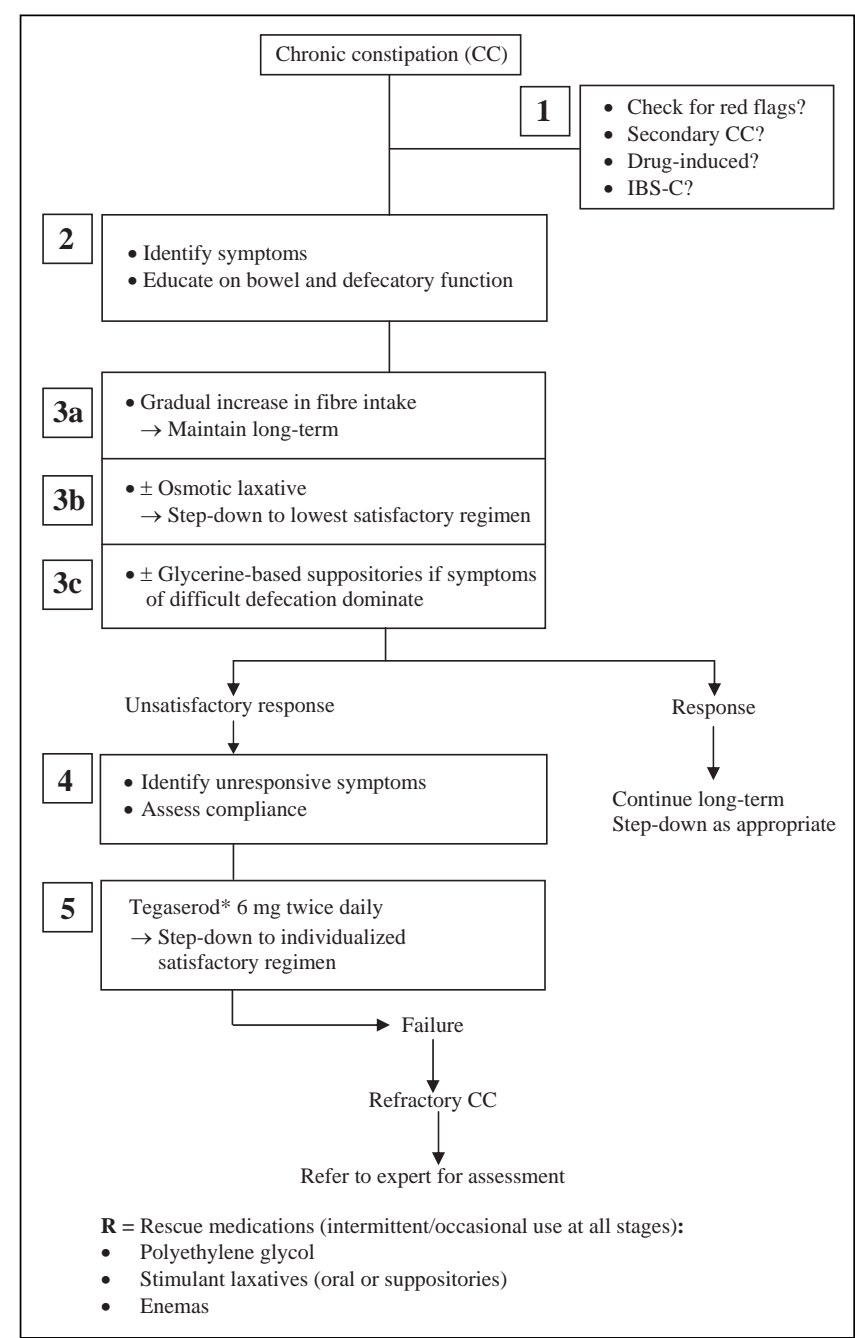

Figure 1) Management algorithm for chronic constipation. *See 'Important Note' at the end of the paper

fibre in healthy individuals. However, in elderly or disabled patients, fluid intake may be compromised (perhaps due to abnormal thirst mechanisms) and therefore should be enforced.

\section{Box $3 b$}

Improvement with fibre may not occur rapidly or rapidly enough to meet patients' expectations. Therefore, more aggressive treatment may be needed. Osmotic laxatives are easy to use and the dose can be titrated to a satisfactory response. $\mathrm{MgOH}$ is an inexpensive agent, while PEG and lactulose are more expensive. Lactulose use is often limited by its gas-producing effect due to its bacterial metabolism. No studies have assessed the long-term use of $\mathrm{MgOH}$ or lactulose. In practice, they usually have to be taken long-term. However, patients should be encouraged to step down therapy to the lowest satisfactory regimen.

\section{Box 3c}

Although disordered defecatory symptoms and physiology do not correlate, symptoms clinically ascribed to difficult defecation are very frequent in patients with CC (31). Furthermore, after fibre intake these symptoms only improve in a small proportion of patients (259), and they may become or remain troublesome in many patients. If symptoms of difficult defecation 
dominate, rectal suppositories (glycerine-based) to initiate rectal evacuation could be used long term as needed.

\section{Box 4}

An unsatisfactory response to therapy should be assessed by reviewing the response of individual symptoms of constipation, the degree of change in quality of life and the adverse effects that could be managed. Patients may have expectations for the relief of symptoms unrelated to constipation or of bowel symptoms, such as bloating and pain, that are not usually responsive to fibre intake and use of laxatives. A diary recording stool frequency, consistency and ease of defecation could be a useful strategy to understand the patient's response to therapy. Education may need to be reinforced to ensure patient compliance with recommended therapies.

\section{Box 5}

Tegaserod is a prokinetic agent shown to be effective in treating patients with $\mathrm{CC}(\mathrm{NNT}=7)$ and those with IBS-C $(\mathrm{NNT}=14)$. In Canada, it is approved for long-term use. If a patient responds to tegaserod, a long-term step-down approach to an individualized regimen could be efficacious in meeting the patient's expectations and in decreasing costs. Tegaserod is the preferred treatment after failure of initial management strategies, rather than using stimulant laxatives. Although tegaserod is effective in treating constipation (improving both frequency of bowel movements and ease of defecation), it is not included as first-line therapy because of its higher cost and higher NNT compared with osmotic laxatives. If and when an unsatisfactory response to initial management strategies occurs, continuation of long-term fibre intake must be encouraged. Patients may have difficulty using osmotic laxatives long term and may require other therapies or the use of various therapies in alternating regimens. If this management strategy fails, it is possible that the patient has refractory CC and should be referred to an expert for further assessment.

\section{REFERENCES}

1. Nyam DC, Pemberton JH, Ilstrup DM, Rath DM. Long-term results of surgery for chronic constipation. Dis Colon Rectum 1997;40:273-9.

2. Gonlachanvit S, Patcharatrakul T. Causes of idiopathic constipation in Thai patients: Associations between the causes and constipation symptoms as defined in the Rome II criteria. J Med Assoc Thai 2004;87(Suppl 2):S22-8

3. Prather CM. Subtypes of constipation: Sorting out the confusion. Rev Gastroenterol Disord 2004;4(Suppl 2):S11-6.

4. Herve S, Savoye G, Behbahani A, Leroi AM, Denis P, Ducrotte P. Results of 24-h manometric recording of colonic motor activity with endoluminal instillation of bisacodyl in patients with severe chronic slow transit constipation. Neurogastroenterol Motil 2004;16:397-402.

5. Rao SS, Sadeghi P, Beaty J, Kavlock R. Ambulatory 24-hour colonic manometry in slow-transit constipation. Am J Gastroenterol 2004:99:2405-16.

6. Bassotti G, Chistolini F, Marinozzi G, Morelli A. Abnormal colonic propagated activity in patients with slow transit constipation and constipation-predominant irritable bowel syndrome. Digestion 2003;68:178-83.

7. Hagger R, Kumar D, Benson M, Grundy A. Colonic motor activity in slow-transit idiopathic constipation as identified by $24-\mathrm{h}$ pancolonic ambulatory manometry. Neurogastroenterol Motil 2003; 15:515-22.

8. Lundin E, Karlbom U, Westlin JE, et al. Scintigraphic assessment of slow transit constipation with special reference to right- or left-sided colonic delay. Colorectal Dis 2004;6:499-505.

9. Rao SS, Sadeghi P, Batterson K, Beaty J. Altered periodic rectal motor activity: A mechanism for slow transit constipation.

Neurogastroenterol Motil 2001;13:591-8.

\section{Box R: Rescue medications}

Stimulant laxatives can be used as rescue medications. These agents cause abdominal cramps and patients may not be able to control or predict the stool response. Stimulant laxatives have been associated with tachyphylaxis and dependency, which can lead to increases in dosage and cost. PEG can be used as a rescue medication and also chronically. In some patients, enemas (preferably small-volume phosphate solutions) can also be used as rescue therapy. Long-term use of stimulant laxatives (oral or suppositories) and/or enemas should be avoided.

\section{APPENDIX - CONSENSUS GROUP MEMBERS}

Co-chairs: S Collins (pathophysiology and probiotics), P Paré (epidemiology and quality of life)

Nonvoting chair: P Moayyedi

Nonvoting participant: N Flook

Voting participants: $\mathrm{R}$ Bridges (behavioural therapy), M Champion (prokinetics), SC Ganguli (osmotic agents), JR Gray (stimulant laxatives, suppositories, enemas and surgery), EJ Irvine (definition and diagnostic criteria), V Plourde (other drugs), P Poitras (bulk-forming agents and stool softeners), GK Turnbull (lifestyle changes)

CONFLICTS OF INTEREST: The following authors have an affiliation with a company or receive remuneration or royalties from a commerical organization: Dr P Paré - Axcan Pharma (speaker and research), Dynogen (research) and Novartis (speaker, advisory board and research); Dr SC Ganguli - Novartis (consensus development, speaker and research); Dr SM Collins - AstraZeneca (advisory board and research), Nestle (research) and Novartis (speaker); and Dr G Turnbull - Novartis (advisory board and research).

IMPORTANT NOTE: At Health Canada's request, as of March 30, 2007, Novartis Pharmaceuticals Canada Inc has suspended the marketing and sales of Zelnorm* (tegaserod hydrogen maleate) in Canada. *Zelnorm is a registered trademark.

10. Penning C, Steens J, van der Schaar PJ, et al. Motor and sensory function of the rectum in different subtypes of constipation. Scand J Gastroenterol 2001;36:32-8.

11. Scott SM, Picon L, Knowles CH, et al. Automated quantitative analysis of nocturnal jejunal motor activity identifies abnormalities in individuals and subgroups of patients with slow transit constipation. Am J Gastroenterol 2003;98:1123-34.

12. Hemingway DM, Finlay IG. Effect of colectomy on gastric emptying in idiopathic slow-transit constipation. Br J Surg 2000;87:1193-6.

13. Penning C, Vu MK, Delemarre JB, Masclee AA. Proximal gastric motor and sensory function in slow transit constipation. Scand J Gastroenterol 2001;36:1267-73.

14. Mollen RM, Hopman WP, Oyen WJ, Kuijpers HH, Edelbroek MA, Jansen JB. Effect of subtotal colectomy on gastric emptying of a solid meal in slow-transit constipation. Dis Colon Rectum 2001;44:1189-95.

15. He CL, Burgart L, Wang L, et al. Decreased interstitial cell of Cajal volume in patients with slow-transit constipation. Gastroenterology 2000;118:14-21.

16. Lyford GL, He CL, Soffer E, et al. Pan-colonic decrease in interstitial cells of Cajal in patients with slow transit constipation. Gut 2002;51:496-501.

17. Wedel T, Spiegler J, Soellner S, et al. Enteric nerves and interstitial cells of Cajal are altered in patients with slow-transit constipation and megacolon. Gastroenterology 2002;123:1459-67.

18. Faussone-Pellegrini MS, Infantino A, Matini P, Masin A, Mayer B, Lise M. Neuronal anomalies and normal muscle morphology at the hypomotile ileocecocolonic region of patients affected by idiopathic chronic constipation. Histol Histopathol 1999;14:1119-34. 
19. Tomita R, Fujisaki S, Ikeda T, Fukuzawa M. Role of nitric oxide in the colon of patients with slow-transit constipation. Dis Colon Rectum 2002;45:593-600.

20. Bassotti G, Villanacci V, Maurer CA, et al. The role of glial cells and apoptosis of enteric neurones in the neuropathology of intractable slow transit constipation. Gut 2006;55:41-6.

21. Zhao RH, Baig MK, Mack J, Abramson S, Woodhouse S, Wexner SD. Altered serotonin immunoreactivities in the left colon of patients with colonic inertia. Colorectal Dis 2002;4:56-60.

22. Zhao RH, Baig MK, Thaler KJ, et al. Reduced expression of serotonin receptor(s) in the left colon of patients with colonic inertia. Dis Colon Rectum 2003;46:81-6.

23. Bharucha AE, Fletcher JG, Seide B, Riederer SJ, Zinsmeister AR. Phenotypic variation in functional disorders of defecation. Gastroenterology 2005;128:1199-210.

24. Leroi AM, Berkelmans I, Denis P, Hemond M, Devroede G. Anismus as a marker of sexual abuse. Consequences of abuse on anorectal motility. Dig Dis Sci 1995;40:1411-6.

25. Klauser AG, Voderholzer WA, Heinrich CA, Schindlbeck NE, Muller-Lissner SA. Behavioral modification of colonic function. Can constipation be learned? Dig Dis Sci 1990;35:1271-5.

26. Voderholzer WA, Neuhaus DA, Klauser AG, Tzavella K, Muller-Lissner SA, Schindlbeck NE. Paradoxical sphincter contraction is rarely indicative of anismus. Gut 1997;41:258-62.

27. Schouten WR, Briel JW, Auwerda JJ, et al. Anismus: Fact or fiction? Dis Colon Rectum 1997;40:1033-41.

28. Gosselink MJ, Schouten WR. Rectal sensory perception in females with obstructed defecation. Dis Colon Rectum 2001;44:1337-44.

29. Gosselink MJ, Hop WC, Schouten WR. Rectal compliance in females with obstructed defecation. Dis Colon Rectum 2001:44:971-7.

30. Dinning PG, Bampton PA, Andre J, et al. Abnormal predefecatory colonic motor patterns define constipation in obstructed defecation. Gastroenterology 2004;127:49-56.

31. Mertz H, Naliboff B, Mayer EA. Symptoms and physiology in severe chronic constipation. Am J Gastroenterol 1999;94:131-8.

32. Schmulson M, Chang L, Naliboff B, Lee OY, Mayer EA. Correlation of symptom criteria with perception thresholds during rectosigmoid distension in irritable bowel syndrome patients. Am J Gastroenterol 2000;95:152-6.

33. Prior A, Maxton DG, Whorwell PJ. Anorectal manometry in irritable bowel syndrome: Differences between diarrhoea and constipation predominant subjects. Gut 1990;31:458-62.

34. Harraf F, Schmulson M, Saba L, et al. Subtypes of constipation predominant irritable bowel syndrome based on rectal perception. Gut 1998;43:388-94.

35. Gladman MA, Dvorkin LS, Lunniss PJ, Williams NS, Scott SM. Rectal hyposensitivity: A disorder of the rectal wall or the afferent pathway? An assessment using the barostat. Am J Gastroenterol 2005;100:106-14

36. Bouin M, Plourde V, Boivin M, et al. Rectal distention testing in patients with irritable bowel syndrome: Sensitivity, specificity, and predictive values of pain sensory thresholds. Gastroenterology 2002;122:1771-7.

37. Canadian Association of Gastroenterology Web site: Policies. $<$ www.cag-acg.org/guidelines/policies.htm>. (Version current at March 14, 2007).

38. Hearnshaw HM, Harker RM, Cheater FM, Baker RH, Grimshaw GM. Expert consensus on the desirable characteristics of review criteria for improvement of health care quality. Qual Health Care 2001;10:173-8.

39. Dent J, Armstrong D, Delaney B, Moayyedi P, Talley NJ, Vakil N. Symptom evaluation in reflux disease: Workshop background, processes, terminology, recommendations, and discussion outputs. Gut 2004;53(Suppl 4):iv1-24.

40. Pare P, Ferrazzi S, Thompson WG, Irvine EJ, Rance L. An epidemiological survey of constipation in Canada: Definition, rates, demographics and predictors of health care seeking. Am J Gastroenterol 2001;96:3130-7.

41. Talley NJ, Weaver AL, Zinsmeister AR, Melton J III. Functional constipation and outlet delay: A population-based study. Gastroenterology 1993;105:781-90.

42. Drossman DA, Li Z, Andruszzi E, et al. US householder survey of functional gastrointestinal disorders. Prevalence, sociodemography, and health impact. Dig Dis Sci 1993;38:1569-80.

43. Stewart WF, Liberman JN, Sandler RS, et al. Epidemiology of constipation (EPOC) study in the United States: Relation of clinical subtypes to sociodemographic features. Am J Gastroenterol 1999;94:3530-40.

44. Higgins PD, Johanson JF. Epidemiology of constipation in North America: A systematic review. Am J Gastroenterol 2004;99:750-9.

45. Thompson WG, Irvine EJ, Pare P, Ferrazzi S, Rance L. Functional gastrointestinal disorders in Canada: First population-based survey using Rome II criteria with suggestions for improving the questionnaire. Dig Dis Sci 2002;47:225-35.

46. Talley NJ, Zinsmeister AR, Melton J III. Irritable bowel syndrome in a community: Symptom subgroups, risk factors, and health care utilization. Am J Epidemiol 1995;142:76-83.

47. Hungin AP, Chang L, Locke GR, Dennis EH, Barghout V. Irritable bowel syndrome in the United States: Prevalence, symptom patterns and impact. Aliment Pharmacol Ther 2005;21:1365-75.

48. Dennison C, Prasad M, Lloyd A, Bhattacharyya SK, Dhawan R, Coyne $\mathrm{K}$. The health-related quality of life and economic burden of constipation. Pharmacoeconomics 2005;23:461-76.

49. Irvine EJ, Ferrazzi S, Pare P, Thompson WG, Rance L. Health-related quality of life in functional GI disorders: Focus on constipation and resource utilization. Am J Gastroenterol 2002;97:1986-93.

50. Ware JE, Show K, Kosnski M, Gandek B. SF-36 Health Survey: Manual and interpretation guide. Boston: The Health Institute, New England Medical Center, 1993.

51. Lalonde L, Clarke AE, Joseph L, Mackenzie T, Grover SA; for the Canadian Collaborative Cardiac Assessment Group. Health-related quality of life with coronary heart disease prevention and treatment. J Clin Epidemiol 2001;54:1011-8.

52. Juniper EF, Norman GR, Cox FM, Roberts JN. Comparison of the standard gamble, rating scale, AQLQ and SF-36 for measuring quality of life in asthma. Eur Respir J 2001;18:38-44.

53. Husted JA, Gladman DD, Farewell VT, Cook RJ. Health-related quality of life of patients with psoriatic arthritis: A comparison with patients with rheumatoid arthritis. Arthritis Care Res 2001;45:151-8.

54. Glia A, Lindberg G. Quality of life in patients with different types of functional constipation. Scand J Gastroenterol 1997;32:1083-9.

55. Damon H, Dumas P, Mion F. Impact of anal incontinence and chronic constipation on quality of life. Gastroenterol Clin Biol 2004;28:16-20.

56. Marquis P, De La Loge C, Dubois D, McDermott A, Chassany O. Development and validation of the Patient Assessment of Constipation Quality of Life questionnaire. Scand J Gastroenterol 2005;40:540-51

57. Li FX, Patten SB, Hilsden RJ, Sutherland LR. Irritable bowel syndrome and health-related quality of life: A population-based study in Calgary, Alberta. Can J Gastroenterol 2003;17:259-63.

58. El-Serag HB, Olden K, Bjorkman D. Health-related quality of life among persons with irritable bowel syndrome: A systematic review. Aliment Pharmacol Ther 2002;16:1171-85.

59. Groll D, Vanner SJ, Depew WT, et al. The IBS-36: A new quality of life measure for irritable bowel syndrome. Am J Gastroenterol 2002;97:962-71.

60. Tillisch K, Labus JS, Naliboff BD, et al. Characterization of the alternating bowel habits subtype in patients with irritable bowel syndrome. Am J Gastroenterol 2005;110:896-904.

61. Gralnek IM, Hays RD, Kilbourne A, Naliboff B, Mayer EA. The impact of irritable bowel syndrome on health-related quality of life. Gastroenterology 2000;119:654-60.

62. Frank L, Kleinman L, Rentz A, Ciesla G, Kim JJ, Zacker C. Health-related quality of life associated with irritable bowel syndrome: Comparison with other chronic diseases. Clin Ther 2002;24:675-89.

63. Patrick DL, Drossman DA, Frederick IO, Dicesare J, Puder KL. Quality of life in persons with irritable bowel syndrome: Development and validation of a new measure. Dig Dis Sci 1998;43:400-11.

64. Wilson A, Longstreth GF, Knight K, et al. Quality of life in managed care patients with irritable bowel syndrome. Managed Care Interface 2004;17:24-28,34.

65. Spiegel BM, Gralnek IM, Bolus R, et al. Clinical determinants of health-related quality of life in patients with irritable bowel syndrome. Arch Intern Med 2004;164:1773-80.

66. Thompson WG. Irritable bowel syndrome: A management strategy. Baillieres Best Pract Res Clin Gastroenterol 1999;13:453-60.

67. Whitehead WE, Wald A, Diamant NE, Enck P, Pemberton JH, Rao SS. Functional disorders of the anus and rectum. Gut 1999;45(Suppl 2):II55-9. 
68. Rao SS, Mudipalli RS, Stessman M, Zimmerman B. Investigation of the utility of colorectal function tests and Rome II criteria in dyssynergic defecation (Anismus). Neurogastroenterol Motil 2004;16:589-96.

69. Connell AM. The motility of the pelvic colon II. Paradoxical motility in diarrhoea and constipation. Gut 1962;3:342-8.

70. Moore-Gillon V. Constipation: What does the patient mean? J R Soc Med 1984;77:108-10.

71. Probert CS, Emmett PM, Cripps HA, Heaton KW. Evidence for the ambiguity of the term constipation: The role of irritable bowel syndrome. Gut 1994;35:1455-8.

72. Longstreth G, Thompson W, Chey W, Houghton L, Mearin F, Spiller R. Functional bowel disorders. Gastroenterology 2006;130:1480-91.

73. Bharucha AE, Wald A, Enck P, Rao S. Functional anorectal disorders. Gastroenterology 2006;130:1510-8.

74. Ferrazzi S, Thompson GW, Irvine EJ, et al. Diagnosis of constipation in family practice. Can J Gastroenterol 2002;16:159-64.

75. Walter S, Hallbook R, Gotthard M, et al. A population based study on bowel habits in a Swedish community: Prevalence of fecal incontinence and constipation. Scand J Gastroenterol 2002;37:911-6.

76. Drossman DA, Morris CB, Hu Y, et al. A prospective assessment of bowel habit in irritable bowel syndrome in women: Defining an alternator. Gastroenterology 2005;128:580-9.

77. Manning AP, Thompson WG, Heaton KW, Morris AF. Towards positive diagnosis of the irritable bowel. Br Med J 1978;2:653-4.

78. Kruis W, Thieme C, Weinzierl M, Schussler P, Holl J, Paulus W. A diagnostic score for the irritable bowel syndrome. Its value in the exclusion of organic disease. Gastroenterology 1984;87:1-7.

79. Vanner SJ, Depew WT, Paterson WG, et al. Predictive value of the Rome criteria for diagnosing irritable bowel syndrome. Am J Gastroenterol 1999;94:2912-7.

80. Hammer J, Eslick GD, Howell SC, Altiparmak E, Talley NJ. Diagnostic yield of alarm features in irritable bowel syndrome. Gut 2004;53:666-73.

81. Rao SS, Ozturk R, Laine L. Clinical utility of diagnostic tests for constipation in adults: A systematic review. Am J Gastroenterol 2005;100:1605-15.

82. Canadian Association of Gastroentorology. Clinical Practice Guidelines and Consensus Reports. <www.cag-acg.org/guidelines/ guidelines.htm> (Version current at March 23, 2007)

83. Muller-Lissner SA, Kamm MA, Scarpignato C, Wald AW. Myths and misconceptions about chronic constipation. Am J Gastroenterol 2005;100:232-42.

84. Aichbichler BW, Wenzl HH, Santa Ana CA, Porter JL, Schiller LR, Fordtran JS. A comparison of stool characteristics from normal and constipated people. Dig Dis Sci 1998;43:2353-62.

85. Ueki A, Otsuka M. Life style risks of Parkinson's disease: Association between decreased water intake and constipation. J Neurol 2004;251(Suppl 7):vII18-23.

86. Robson KM, Kiely DK, Lembo T. Development of constipation in nursing home residents. Dis Colon Rectum 2000;43:940-3.

87. Lindeman RD, Romero LJ, Liang HC, et al. Do elderly persons need to be encouraged to drink more fluids? J Gerontol A Biol Sci Med Sci 2000;55:M361-5.

88. Anti M, Pignataro G, Armuzzi A, et al. Water supplementation enhances the effect of high-fiber diet on stool frequency and laxative consumption in adult patients with functional constipation. Hepatogastroenterology 1998;45:727-32.

89. Preston DM, Lennard-Jones JE. Severe chronic constipation of young women: 'Idiopathic slow transit constipation'. Gut 1986;27:41-8

90. Anderson AS. Dietary factors in the aetiology and treatment of constipation during pregnancy. Br J Obstet Gynecol 1986;93:245-9.

91. Klauser AG, Peyerl C, Schindlbeck NE, et al. Nutrition and physical activity in chronic constipation. Eur J Gastroenterol Hepatol 1992;4:227-33.

92. Towers AL, Burgio KL, Locher JL, et al. Constipation in the elderly: Influence of dietary, psychological, and physiological factors. J Am Geriatr Soc 1994;42:701-6.

93. Chung BD, Parekh U, Sellin JH. Effect of increased fluid intake on stool output in normal healthy volunteers. J Clin Gastroenterol 1999;28:29-32.

94. Klauser AG, Beck A, Schindlbeck NE, et al. Low fluid intake lowers stool output in healthy male volunteers. Z Gastroenterol 1990;28:606-9.
95. Bingham SA, Vorster H, Jerling JC, et al. Effect of black tea drinking on blood lipids, blood pressure and aspects of bowel habit. Br J Nutr 1997;78:41-55.

96. Wong ML, Wee S, Pin CH, Gan GL, Ye HC. Sociodemographic and lifestyle factors associated with constipation in an elderly Asian community. Am J Gastroenterol 1999;94:1283-91.

97. Zieghagen DJ, Tewinkel G, Kruis W, et al. Adding more fluid to wheat bran has no significant effects on intestinal functions in healthy subjects. J Clin Gastroenterol 1991;13:525-30.

98. Muller-Lissner SA. Effect of wheat bran on weight of stool and gastrointestinal transit time: A meta analysis. Br Med J 1988;296:615-7.

99. Cook IJ, Irvine EJ, Campbell D, Shannon S, Reddy SN, Collins SM. Effect of dietary fiber on symptoms and rectosigmoid motility in patients with irritable bowel syndrome. Gastroenterology 1990;98:66-72.

100. Lambert JP, Brunt PW, Mowat NAG, et al. The value of prescribed "high-fibre" diets for the treatment of the irritable bowel syndrome. Eur J Clin Nutr 1991;45:601-9.

101. Bosaeus I. Fibre effects on intestinal functions (diarrhoea, constipation and irritable bowel syndrome). Clin Nutr Suppl 2004;1:33-8.

102. Francis CY, Whorwell PJ. Bran and irritable bowel syndrome: Time for reappraisal. Lancet 1994;344:39-40.

103. Brown WJ, Mishra G, Lee C, et al. Leisure time physical activity in Australian women: Relationship with well being and symptoms. Res Q Exerc Sport 2000;71:206-16.

104. Sullivan SN, Wong C, Heidenheim P. Does running cause gastrointestinal symptoms? A survey of 93 randomly selected runners compared with controls. N Z Med J 1994;107:328-31.

105. Tuteja AK, Talley NJ, Joos SK, Woehl JV, Hickram DH. Is constipation associated with decreased physical activity in normally active subjects? Am J Gastroenterol 2005;100:124-9.

106. Coenen C, Wegener M, Wedmann B, Schmidt G, Hoffmann S. Does physical excercise influence bowel transit time in healthy young men. Am J Gastroenterol 1992;87:292-5.

107. Meshkinpour H, Kemp C, Fairshter R. Effect of aerobic exercise on mouth-to-cecum transit time. Gastroenterology 1989;96:938-41.

108. Soffer EE, Sumers RW, Gisolfi C. Effect of exercise on intestinal motility and transit in trained athletes. Am J Physiol 1991;260:G698-702.

109. Meshkinpour H, Selod S, Movahedi H, et al. Effects of regular exercise in management of chronic idiopathic constipation. Dig Dis Sci 1998;43:2379-83.

110. Bingham SA, Cummings JH. Effect of exercise and physical fitness on large intestinal function. Gastroenterology 1989;97:1389-99.

111. Rao SS, Beaty J, Chamberlain M, Lambert PG, Gisolfi C. Effects of acute graded exercise on human colonic motility. Am J Physiol 1999;276:G1221-6.

112. Donald IP, Smith RG, Cruikshank JG, et al. A study of constipation in the elderly living at home. Gerontology 1985;31:112-8.

113. Kinnunen O. Study of constipation in a geriatric hospital, day hospital, old people's home and at home. Aging 1991;3:112-8.

114. Fenn GC, Wilkinson PD, Lee CE, Akbar FA. A general practice study of the efficacy of Regulan in functional constipation. Br J Clin Pract 1986;40:192-7.

115. Ashraf W, Park F, Lof J, Quigley EM. Effects of psyllium therapy on stool characteristics, colon transit and anorectal function in chronic idiopathic constipation. Aliment Pharmacol Ther 1995;9:639-47.

116. Cheskin LJ, Kamal N, Crowell MD, Schuster MM, Whitehead WE. Mechanisms of constipation in older persons and effects of fiber compared with placebo. J Am Geriatr Soc 1995;43:666-9.

117. McRorie JW, Daggy BP, Morel JG, Diersing PS, Miner PB, Robinson M. Psyllium is superior to docusate sodium for treatment of chronic constipation. Aliment Pharmacol Ther 1998;12:491-7.

118. Ritchie JA, Truelove SC. Treatment of irritable bowel syndrome with lorazepam, hyoscine butylbromide, and ispaghula husk. Br Med J 1979;1:376-8.

119. Ritchie JA, Truelove SC. Comparison of various treatments for irritable bowel syndrome. Br Med J 1980;281:1317-9.

120. Nigam P, Kapoor KK, Rastog CK, Kumar A, Gupta AK. Different therapeutic regimens in irritable bowel syndrome. J Assoc Physicians India 1984;32:1041-4

121. Prior A, Whorwell PJ. Double blind study of ispaghula in irritable bowel syndrome. Gut 1987;28:1510-3.

122. Golechha AC, Chadda VS, Chadda S, Sharma SK, Mishra SN. Role of ispaghula husk in the management of irritable bowel 
syndrome (a randomized double-blind crossover study). J Assoc Physicians India 1982;30:353-5.

123. Longstreth GF, Fox DD, Youkeles L, Forsythe AB, Wolochow DA. Psyllium therapy in the irritable bowel syndrome. Ann Intern Med 1981;95:53-6.

124. Arthurs Y, Fielding JF. Double blind trial of ispaghula/poloxamer in the irritable bowel syndrome. Ir Med J 1983;76:253.

125. Hamilton JW, Wagner J, Burdick BB, Bass P. Clinical evaluation of methylcellulose as a bulk laxative. Dig Dis Sci 1988;33:993-8.

126. Toskes PP, Connery KL, Ritchey TW. Calcium polycarbophil compared with placebo in irritable bowel syndrome. Aliment Pharmacol Ther 1993; 7:87-92.

127. Hyland CM, Foran JD. Dioctyl sodium sulphosuccinate as a laxative in the elderly. Practitioner 1968;200:698-9.

128. Castle SC, Cantrell M, Israel DS, Samuelson MJ. Constipation prevention: Empiric use of stool softeners questioned. Geriatrics 1991;46:84-6.

129. Fain AM, Susat R, Herring M, Dorton K. Treatment of constipation in geriatric and chronically ill patients: A comparison. South Med J 1978;71:677-80.

130. Chapman RW, Sillery J, Fontana DD, Matthys C, Saunders DR. Effect of oral dioctyl sodium sulfosuccinate on intake-output studies of human small and large intestine. Gastroenterology 1985;89:489-93.

131. Sharif F, Crushell E, O'Driscoll K, Bourke B. Liquid paraffin: A reappraisal of its role in the treatment of constipation. Arch Dis Child 2001;85:121-4.

132. Kinnunen O, Salokannel J. Constipation in elderly long-stay patients: Its treatment by magnesium hydroxide and bulk laxative. Ann Clin Res 1987;19:321-3.

133. Andorsky RI, Goldner F. Colonic lavage solution (polyethylene glycol electrolyte lavage solution) as a treatment for chronic constipation: A double-blind, placebo-controlled study. Am J Gastroenterol 1990;85:261-5.

134. Klauser AG, Muhldorfer BE, Volderholzer WA, Wenzel G, Muller-Lissner SA. Polyethylene glycol 4000 for slow transit constipation. Z Gastroenterol 1995;33:5-8.

135. Corazziari E, Badiali D, Habib FI, et al. Small volume isosmotic polyethylene glycol electrolyte balanced solution (PMF-100) in treatment of chronic nonorganic constipation. Dig Dis Sci 1996;41:1636-42.

136. Freedman MD, Schwartz JH, Roby R, Fleisher S. Tolerance and efficacy of polyethylene glycol 3350/electrolyte solution versus lactulose in relieving opiate induced constipation: A doubleblinded placebo-controlled trial. J Clin Pharmacol 1997;37:904-7.

137. Attar A, Lemann M, Ferguson A, et al. Comparison of a low dose polyethylene glycol electrolyte solution with lactulose for treatment of chronic constipation. Gut 1999;44:226-30.

138. Bassotti G, Fiorella S, Roselli P, Modesto R. Use of polyethylene glycol solution in slow transit constipation. Ital J Gastroenterol Hepatol 1999;31(Supp 3):S255-6.

139. Cleveland MV, Flavin DP, Ruben RA, Epstein RM, Clark GE. New polyethylene glycol laxative for treatment of constipation in adults: A randomized, double-blind, placebo-controlled study. South Med J 2001;94:478-81.

140. DiPalma JA, DeRidder PH, Orlando RC, Kolts BE, Cleveland MB. A randomized, placebo-controlled, multicenter study of the safety and efficacy of a new polyethylene glycol laxative. Am J Gastro 2000;95:446-50.

141. DiPalma JA, Smith JR, Cleveland MB. Overnight efficacy of polyethylene glycol laxative. Am J Gastroenterol 2002;97:1776-9.

142. Corazziari E, Badiali D, Bazzocchi G, et al. Long term efficacy, safety, and tolerabilitity of low daily doses of isosmotic polyethylene glycol electrolyte balanced solution (PMF-100) in the treatment of functional chronic constipation. Gut 2000;46:522-6.

143. Sanders JF. Lactulose syrup assessed in a double-blind study of elderly constipated patients. J Am Geriatr Soc 1978;26:236-9.

144. Wesselius-De Casparis A, Braadbaart S, Bergh-Bohlken GE, Mimica M. Treatment of chronic constipation with lactulose syrup: Results of a double-blind study. Gut 1968;9:84-6.

145. Rouse M, Chapman N, Mahapatra M, Grillage M, Atkinson SN, Prescott P. An open, randomised, parallel group study of lactulose versus ispaghula in the treatment of chronic constipation in adults. Br J Clin Pract 1991;45:28-30.

146. Cann PA. Oral domperidone double blind comparison with placebo in IBS. Gut 1983;24:1135-4.
147. Fielding JF. Domperidone treatment in the IBS. Digestion 1982;23:577-84

148. Milo R. Use of domperidone in the management of gastrointestinal symptoms in patients with IBS. Curr Med Res Opin 1980;6:577-84

149. Chang L, Cohard-Radice M, Dunger-Baldauf C, et al. Tegaserod is effective for long-term use in patients with chronic constipation. Digestive Disease Week. Los Angeles, May 20 to 25, 2006. Abstract T2039.

150. Muller-Lissner S, Kamm MA, Musoglu A, Earnest DL, Dunger-Baldauf C, Shetzline MA. Safety, tolerability, and efficacy of tegaserod over 13 months in patients with chronic constipation. Am J Gastroenterol 2006;101:2558-69.

151. Kamm MA, Muller-Lissner S, Talley NJ, et al. Tegaserod for the treatment of chronic constipation: A randomized, double-blind, placebo-controlled multinational study. Am J Gastroenterol 2005;100:362-72.

152. Johanson JF, Wald A, Tougas G, et al. Effect of tegaserod in chronic constipation: A randomized, double-blind, controlled trial. Clin Gastroenterol Hepatol 2004;2:796-805.

153. Johanson JF. Review article: Tegaserod for chronic constipation. Aliment Pharmacol Ther 2004;20(Suppl 7):20-4.

154. Tougas G, Snape WJ Jr, Otten MH, et al. Long-term safety of tegaserod in patients with constipation-predominant irritable bowel syndrome. Aliment Pharmacol Ther 2002;16:1701-8.

155. Tack J, Muller-Lissner S, Bytzer P, et al. A randomised controlled trial assessing the efficacy and safety of repeated tegaserod therapy in women with irritable bowel syndrome with constipation. Gut 2005:54:1707-13.

156. Novick J, Miner P, Krause R, et al. A randomized, double-blind, placebo-controlled trial of tegaserod in female patients suffering from irritable bowel syndrome with constipation. Aliment Pharmacol Ther 2002;16:1877-88.

157. Muller-Lissner SA, Fumagalli I, Bardhan KD, et al. Tegaserod, a $5-\mathrm{HT}(4)$ receptor partial agonist, relieves symptoms in irritable bowel syndrome patients with abdominal pain, bloating and constipation. Aliment Pharmacol Ther 2001;15:1655-66.

158. Layer P, Keller J, Mueller-Lissner S, Ruegg P, Loeffler H. Tegaserod: Long-term treatment for irritable bowel syndrome patients with constipation in primary care. Digestion 2005;71:238-44.

159. Evans BW, Clark WK, Moore DJ, Whorwell PJ. Tegaserod for the treatment of irritable bowel syndrome. Cochrane Database Syst Rev 2004;(1):CD003960.

160. Stern FH. Constipation - an omnipresent symptom: Effect of a preparation containing prune concentrate and cascarin. J Am Geriatr Soc 1966;14:1153-5.

161. Kinnunen O, Winblad I, Koistinen P. Safety and efficacy of a bulk containing laxative containing senna versus lactulose in the treatment of chronic constipation in geriatric patients. Pharmacology 1993;47(Supp 1):253-5.

162. Connolly P, Hughes IW, Ryan G. Comparison of "Duphalac" and "irritant" laxatives during and after treatment of chronic constipation: A preliminary study. Curr Med Res Opin 1975;2:620-5.

163. Pers M, Pers B. A crossover comparative study with two bulk laxatives. J Int Med Res 1983;11:51-3.

164. Williamson J, Coll M, Connolly M. A comparative trial of a new laxative. Nurs Times 1975;71:1705-7.

165. Odes HS, Madar Z. A double-blind trial of Celandin, Alovera and psyllium laxative preparation in adult patients with constipation. Digestion 1991;49:65-71.

166. MacLennan WJ, Pooler AF. A comparison of sodium picosulphate (Laxoberal) with standardised senna (Sennokot) in geriatric patients. Curr Med Res Opin 1975;2:641-7.

167. Passmore AP, Wilson-Davies K, Stoker C, Scott ME. Chronic constipation in long stay elderly patients: A comparison of lactulose and a senna-fibre combination. BMJ 1993;307:769-71.

168. Kasdon SC, Morentin BO. The management of puerperal constipation with a senna preparation. J Int Coll Surg 1959;31:455-8.

169. Katz R. Evaluation of standardized senna in the treatment of refractory constipation. Med Press 1960;243:335-6.

170. Corman ML. Management of postoperative constipation in anorectal surgery. Dis Col Rect 1979;22:149-51.

171. DeLuca VA. The management of chronic functional constipation in the severely incapacitated, aged nursing home patient. Med Counterpoint 1974;6:25-7.

172. Steins AS, Luttrel W, Binard JE. Polyethylene glycol versus vegetable oil based bisacodyl suppositories to initiate side-lying 
bowel care: A clinical trial in persons with spinal cord injury. Spinal Cord 1998;36:777-81.

173. Cornell SA, Campion L, Bacero S. Comparison of three bowel management programs. Nurs Res 1973;22:321-8.

174. Bouchoucha M, Faye A, Savarieau B, Arsac M. Effect of an oral bulking agent and a rectal laxative administered alone or in combination for the treatment of constipation. Gastroenterol Clin Biol 2004;28:438-43.

175. Davies C. The use of phosphate enemas in the treatment of constipation. Nurs Times 2004;100:32-5.

176. Amir I, Sharma R, Bauman WA. Bowel care for individuals with spinal cord injury: Comparison of four approaches. J Spinal Cord Med 1998;21:21-4.

177. Health Canada. Canadian Adverse Reaction Newsletter, Volume 12 Number 2, April 2002. <http://www.hc-sc.gc.ca/dhpmps/medeff/bulletin/carn-bcei_v12n2_e.html> (Version current at March 14, 2007).

178. Poynard T, Regimbeau C, Benhamou Y. Meta-analysis of smooth muscle relaxants in the treatment of irritable bowel syndrome. Aliment Pharmacol Ther 2001;15:355-61

179. Quartero AO, Meineche-Schmidt V, Muris J, Rubin G, de Wit N. Bulking agents, antispasmodic and antidepressant medication for the treatment of irritable bowel syndrome. Cochrane Database Syst Rev 2005;(2):CD003460.

180. Jailwala J, Imperiale TF, Kroenke K. Pharmacologic treatment of the irritable bowel syndrome: A systematic review of randomized, controlled trials. Ann Intern Med 2000;133:136-47.

181. Delegge M, Kaplan R. Efficacy of bowel preparation with the use of a prepackaged, low fibre diet with a low sodium, magnesium citrate cathartic vs a clear liquid diet with a standard sodium phosphate cathartic. Aliment Pharmacol Ther 2005;21:1491-5.

182. Verghese VJ, Ayub K, Qureshi W, Taupo T, Graham DY. Low-salt bowel cleansing preparation (LoSo Prep) as preparation for colonoscopy: A pilot study. Aliment Pharmacol Ther 2002;16:1327-31.

183. Frame PS, Dolan P, Kohli R, Eberly SW. Use of colchicine to treat severe constipation in developmentally disabled patients. J Am Board Fam Pract 1998;11:341-6.

184. Verne GN, Eaker EY, Davis RH, Snisky CA. Colchicine is an effective treatment for patients with chronic constipation: An open-label trial. Dig Dis Sci 1997;42:1959-63.

185. Verne GN, Davis RH, Robinson ME, Gordon JM, Eaker EY, Sninksy CA. Treatment of chronic constipation with colchicine: Randomized, double-blind, placebo-controlled, crossover trial. Am J Gastroenterol 2003;98:1112-6.

186. Soffer EE, Metcalf A, Launspach J. Misoprostol is effective treatment for patients with severe chronic constipation. Dig Dis Sci 1994;39:929-33

187. Roarty TP, Weber F, Soykan I, McCallum RW. Misoprostol in the treatment of chronic refractory constipation: Results of a long-term open label trial. Aliment Pharmacol Ther 1997;11:1059-66.

188. Goldberg AB, Greenberg MB, Darney PD. Drug therapy: Misoprostol and pregnancy. N Engl J Med 2001;344:38-47.

189. Fielding JF. Double blind trial of trimebutine in the irritable bowel syndrome. Ir Med J 1980;73:377-9.

190. Luttecke K. A three-part controlled study of trimebutine in the treatment of irritable colon syndrome. Curr Med Res Opin 1980;6:437-43.

191. Luttecke K. A trial of trimebutine in spastic colon. J Int Med Res 1978;6:86-8.

192. Moshal MG, Herron M. A clinical trial of trimebutine (Mebutin) in spastic colon. J Int Med Res 1979;7:231-4.

193. Schang JC, Devroede G, Pilote M. Effects of trimebutine on colonic function in patients with chronic idiopathic constipation: Evidence for the need of a physiologic rather than clinical selection. Dis Colon Rectum 1993;36:330-6.

194. Emmanuel AV, Kamm MA. Response to a behavioural treatment, biofeedback, in constipated patients is associated with improved gut transit and autonomic innervation. Gut 2001;49:214-9.

195. Enck P. Biofeedback training in disordered defecation: A critical review. Dig Dis Sci 1993;38:1953-60.

196. Rao SC, Welcher KD, Pelsang RE. Effects of biofeedback therapy on anorectal function in obstructive defecation. Dig Dis Sci 1997;42:2197-205.

197. Chiarioni G, Salandini L, Whitehead WE. Biofeedback benefits only patients with outlet obstruction dysfunction, not patients with isolated slow transit constipation. Gastroenterology 2005;129:86-97

198. Chiotakakou-Faliakou E, Kamm MA, Roy AJ, Storrie JB, Turner IC Biofeedback provides long term benefit for patients with intractable, slow and normal transit constipation. Gut 1998;42:517-21.

199. Mason HJ, Serrano-Ikkos E, Kamm MA. Psychological state and quality of life in patients having behavioural treatment (biofeedback) for intractable constipation. Am J Gastroenterol 2002;97:3154-9.

200. Chiarioni G, Whitehead WE, Pezza V, Morelli A, Bassotti G. Biofeedback is superior to laxatives for normal transit constipation due to pelvic floor dyssynergia. Gastroenterology 2006;130:657-64.

201. Battaglia E, Serra AM, Buonafede G, et al. Long-term study on the effects of visual biofeedback and muscle training as therapeutic modality in pelvic floor dyssynergia and slow-transit constipation. Dis Colon Rectum 2004;47:90-5.

202. Wiesel PH, Dorta G, Cuypers P, et al. Patient satisfaction after biofeedback for constipation and pelvic floor dyssynergia. Swiss Med Wkly 2001;131:152-6.

203. Turnbull GK, Ritvo PG. Anal sphincter biofeedback relaxation treatment for women with intractable constipation symptoms. Dis Colon Rectum 1992;35:530-6.

204. Koutsomanis D, Lennard-Jones JE, Roy AJ, Kamm MA. Controlled randomized trial of visual biofeedback versus muscle training without a visual display for intractable constipation. Gut 1995;37:95-9.

205. Rao SS. Biofeedback therapy for dyssynergic (obstructive) defecation. J Clin Gastroenterol 2000;30:115-6.

206. Wang J, Luo MH, Qi QH, Dong ZL. Prospective study of biofeedback retraining in patients with chronic idiopathic functional constipation. World J Gastroenterol 2003;9:2109-13.

207. Heyman S, Wexner SD, Vickers D, Nogueras JJ, Weiss EG, Pikarsky AJ. Prospective, randomized trial comparing four biofeedback techniques for patients with constipation. Dis Colon Rectum 1999;42:1388-93.

208. Diament NE, Kamm MA, Wald A, Whitehead WE. AGA technical review on anorectal testing techniques. Gastroenterology 1999;116:735-60.

209. Bassotti G, Chistolini F, Sietchiping-Nzepa F, de Roberto G, Morelli A, Chiarioni G. Biofeedback for pelvic floor dysfunction in constipation. BMJ 2004;328:393-6.

210. Glia A, Gylin M, Gullberg K, Lindberg G. Biofeedback retraining in patients with functional constipation and paradoxical puborectalis contraction. Dis Colon Rectum 1997;40:889-95.

211. Bleijenberg G, Kuipers HC. Biofeedback treatment of constipation: A comparison of two methods. Am J Gastroenterol 1994;89:1021-6.

212. Gilliland R, Heymen S, Altomare DF, Park UC, Vickers D, Wexner SD. Outcome and predictors of success of biofeedback for constipation. Br J Surg 1997:84:1123-6.

213. Heyman S, Jones KR, Scarlett Y, Whitehead WE. Biofeedback treatment of constipation: A critical review. Dis Colon Rectum 2003;46:1208-17

214. Roy AJ, Emmanuel AV, Storrie J, Kamm MA. Behavioural treatment (biofeedback) for constipation following hysterectomy. Br J Surg 2000;87:100-5.

215. Vaizey CJ, Roy AJ, Kamm MA. Prospective evaluation of the treatment of solitary rectal ulcer syndrome with biofeedback. Gut 1997;41:817-20.

216. Wiesel PH, Norton C, Roy AJ, Storrie JB, Bowers J, Kamm MA. Gut focused behavioural treatment (biofeedback) for constipation and faecal incontinence in multiple sclerosis. J Neurol Neurosurg Psychiatry 2000;69:240-3

217. Whorwell PJ, Prior A, Faragher EB. Controlled trial of hypnotherapy in the treatment of severe refractory irritable bowel syndrome. Lancet 1984;2:1232-4

218. Guthrie E, Creed F, Dawson D, Tomenson B. A controlled trial of psychological treatment for the irritable bowel syndrome. Gastroenterology 1991;100:450-7.

219. Drossman DA, Camilleri M, Mayer EA, Whitehead WE. AGA technical review on irritable bowel syndrome. Gastroenterology 2002;123:2108-31.

220. Drossman DA, Toner BB, Whitehead WE, et al. Cognitive behavioral therapy versus education and desipramine versus placebo for moderate to severe functional bowel disorders. Gastroenterology 2003;125:19-31

221. Drossman DA, Creed FH, Olden KW, et al. Psychosocial aspects of the functional gastrointestinal disorders. Gut 1999;45:1125-30. 
222. Harvey R, Hinton RA, Gunary RM, et al Individual and group hypnotherapy in the treatment of refractory irritable bowel syndrome. Lancet 1989;1:424-5.

223. Vidakovic-Vukic M. Hypnotherapy in the treatment of irritable bowel syndrome: Methods and results in Amsterdam. Scand J Gastroenterol 1999;230:49-51.

224. Whorwell PJ, Prior A, Colgan SM. Hypnotherapy in severe irritable bowel syndrome: Further experience. Gut 1987;28:423-5.

225. Galovski TE, Blanchard EB. The treatment of irritable bowel syndrome with hypnotherapy. Appl Psychophysiol Biofeedback 1998;23:219-32.

226. Gonsalkorale WM, Miller V, Afzal A, Whorwell PJ. Long term benefits of hypnotherapy for irritable bowel syndrome. Gut 2003;52:1623-9

227. Houghton LA, Heyman DJ, Whorwell PJ. Symptomatology, quality of life and economic features of irritable bowel syndrome - the effect of hypnotherapy. Aliment Pharmacol Ther 1996;10:91-5.

228. Palsson OS, Turner MJ, Whitehead WE. Hypnosis home treatment for irritable bowel syndrome. Int J Clin Exp Hypn 2006;54:85-9

229. Whorwell PJ, Houghton LA, Taylor EE, Maxton DG. Physiological effects of emotion: Assessment via hypnosis. Lancet 1992;34:69-72.

230. Houghton LA, Calvert EL, Jackson NA, Cooper P, Whorwell PJ. Visceral sensation and emotion: A study using hypnosis. Gut 2002;51:701-4.

231. Prior A, Colgan SM, Whorwell PJ. Changes in rectal sensitivity after hypnotherapy in patients with irritable bowel syndrome. Gut 1990;31:896-8.

232. Simren M, Ringstrom G, Bjornsson ES, Abrahamsson H. Treatment with hypnotherapy reduces the sensory and motor component of the gastrocolonic response in irritable bowel syndrome. Psychosom Med 2004;66:233-8.

233. Palsson OS, Turner MJ, Johnson DA, Burnelt CK, Whitehead WE Hypnosis treatment for severe irritable bowel syndrome: Investigation of mechanism and effects on symptoms. Dig Dis Sci 2002;47:2605-14

234. Talley NJ, Owen BK, Boyce P, Paterson K. Psychological treatments for irritable bowel syndrome: A critique of controlled treatment trials. Am J Gastroenterol 1996;91:277-83.

235. Blanchard EB, Schwarz SP, Suls JP, et al Two controlled evaluations of multicomponent psychological treatment of irritable bowel syndrome. Behav Res Ther 1992;30:175-89.

236. Greene B, Blanchard EB. Cognitive therapy for irritable bowel syndrome. J Consult Clin Psychol 1994;62:576-82.

237. Payne A, Blanchard EB. A controlled comparison of cognitive therapy and self-help support groups in the treatment of irritable bowel syndrome. J Consult Clin Psychol 1995;63:779-86.

238. Vollmer A, Blanchard EB. Controlled comparison of individual versus group cognitive therapy for irritable bowel syndrome. Behav Ther 1998;29:19-33

239. Van Dulmen AM, Fennis JF, Bleijenberg G. Cognitive-behavioral group therapy as a treatment for irritable syndrome: Effects and long-term follow-up. Psychosom Med 1996;58:508-14.

240. Toner BB, Zegal ZV, Emmott S, et al. Cognitive behavioural group therapy for patients with irritable bowel syndrome. Int J Group Psychother 1998;48:215-43.

241. Boyce P, Gilchrist J, Talley NJ, Rose D. Cognitive-behavioral therapy as a treatment for irritable bowel syndrome: A pilot study. Aust NZ J Psychiatry 2000;34:300-9.

242. Heymann-Monnikes I, Arnold R, Florin I, Herda C, Melfsen S, Monnikes $\mathrm{H}$. The combination of medical treatment plus multi-component behavioral therapy is superior to medical treatment alone in the therapy of irritable bowel syndrome. Am J Gastroenterol 2000;95:981-94.

243. Svedlund J, Sjodin I, Ottosson J, Dotevall G. Controlled study of psychotherapy in irritable bowel syndrome. Lancet 1983;2:589-92.

244. Guthrie E. Brief psychotherapy for patients with refractory irritable bowel syndrome. Br J Psychother 1991;8:175-88.

245. Leibbrand R, Hiller W. Cognitive behavior therapy for functional gastrointestinal disorders: Is group treatment effective? Acta Neuropsychiatrica 2003;15:242-8.

246. Boyce PM, Talley NJ, Balaam B, Koloski NA, Truman G. A randomized controlled trial of cognitive behavioural therapy, relaxation training, and routine clinical care for the irritable bowel syndrome. Am J Gastroenterol 2003;98:2209-18.

247. Creed F, Guthrie E, Ratcliffe J, et al; on behalf of the North of England IBS Research Group. Does psychological treatment help only those patients with severe irritable bowel syndrome who also have a concurrent psychiatric disorder? Aust N Z J Psychiatry 2005;39:807-15

248. Blanchard EB, Lackner JM, Gusmano R, et al. Prediction of treatment outcome among patients with irritable bowel syndrome treated with group cognitive therapy. Behav Res Ther 2006;44:317-37.

249. Corney RH, Stanton R, Newell R, Clare A, Fairclough P. Behavioral psychotherapy in the treatment of irritable bowel syndrome. J Psychosom Res 1991;35:461-9.

250. Knowles CH, Scott M, Lunniss PJ. Outcome of colectomy for slowtransit constipation. Ann Surg 1999;230:627-38.

251. Wexner SD, Daniel N, Jagelman DG. Colectomy for constipation: Physiologic investigation is the key to success. Dis Colon Rectum 1991;34:851-6.

252. Koebnick C, Wagner I, Leitzmann P, Stern U, Zunft HJ. Probiotic beverage containing Lactobacillus casei Shirota improves gastrointestinal symptoms in patients with chronic constipation. Can J Gastroenterol 2003;17:655-9.

253. Niv E, Naftali T, Hallak R, Vaisman N. The efficacy of Lactobacillus reuteri ATCC 55730 in the treatment of patients with irritable bowel syndrome - a double blind, placebo-controlled, randomized study. Clin Nutr 2005;24:925-31.

254. Creed F, Fernandes L, Guthrie E, et al; North of England IBS Research Group. The cost-effectiveness of psychotherapy and paroxetine for severe irritable bowel syndrome. Gastroenterology 2003;124:303-17

255. O'Mahony L, McCarthy J, Kelly P, et al. Lactobacillus and bifidobacterium in irritable bowel syndrome: Symptom responses and relationship to cytokine profiles. Gastroenterology $2005 ; 128: 541-51$.

256. Nobaek S, Johansson ML, Molin G, Ahrne S, Jeppsson B. Alteration of intestinal microflora is associated with reduction in abdominal bloating and pain in patients with irritable bowel syndrome. Am J Gastroenterol 2000;95:1231-8.

257. Kim HJ, Vazquez Roque MI, Camilleri M, et al. A randomized controlled trial of a probiotic combination VSL\# 3 and placebo in irritable bowel syndrome with bloating. Neurogastroenterol Motil 2005; 17:687-96.

258. Niedzielin K, Kordecki H, Birkenfeld B. A controlled, double-blind, randomized study on the efficacy of Lactobacillus plantarum $299 \mathrm{~V}$ in patients with irritable bowel syndrome. Eur J Gastroenterol Hepatol 2001;13:1143-7.

259. Voderholzer WA, Schatke W, Muhldorfer BE, Klauser AG, Birkner B, Muller-Lissner SA. Clinical response to dietary fibre treatment of chronic constipation. Am J Gastroenterol 1997;92:95-8. 


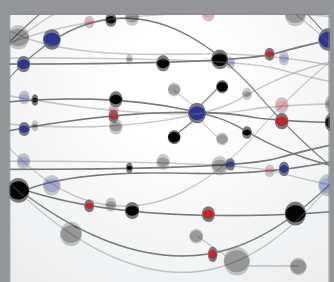

The Scientific World Journal
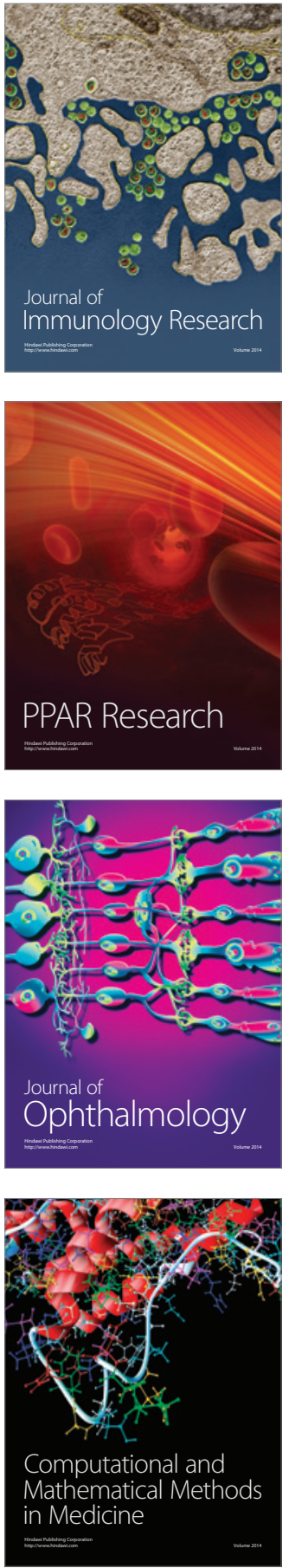

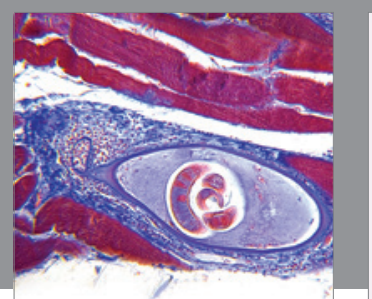

Gastroenterology Research and Practice

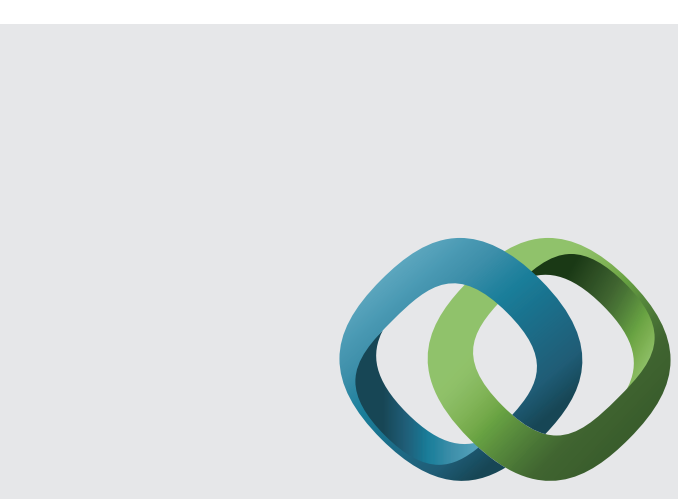

\section{Hindawi}

Submit your manuscripts at

http://www.hindawi.com
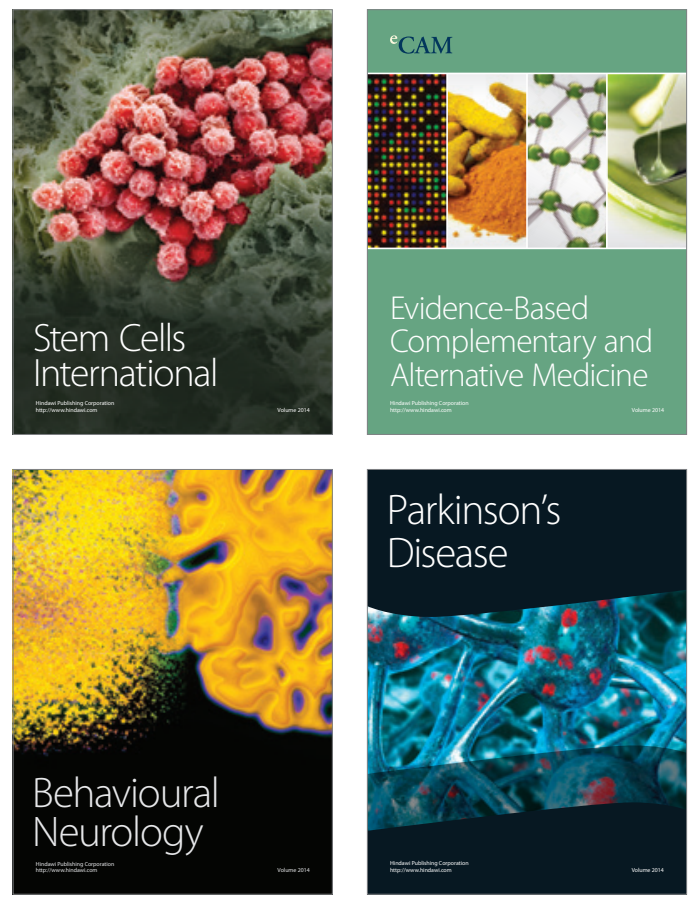
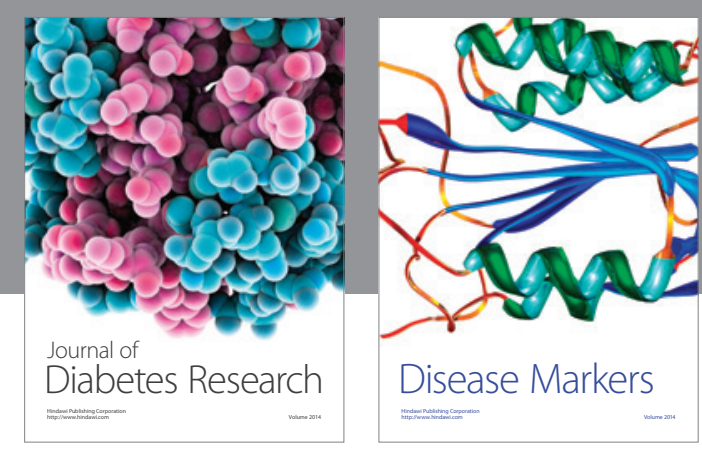

Disease Markers
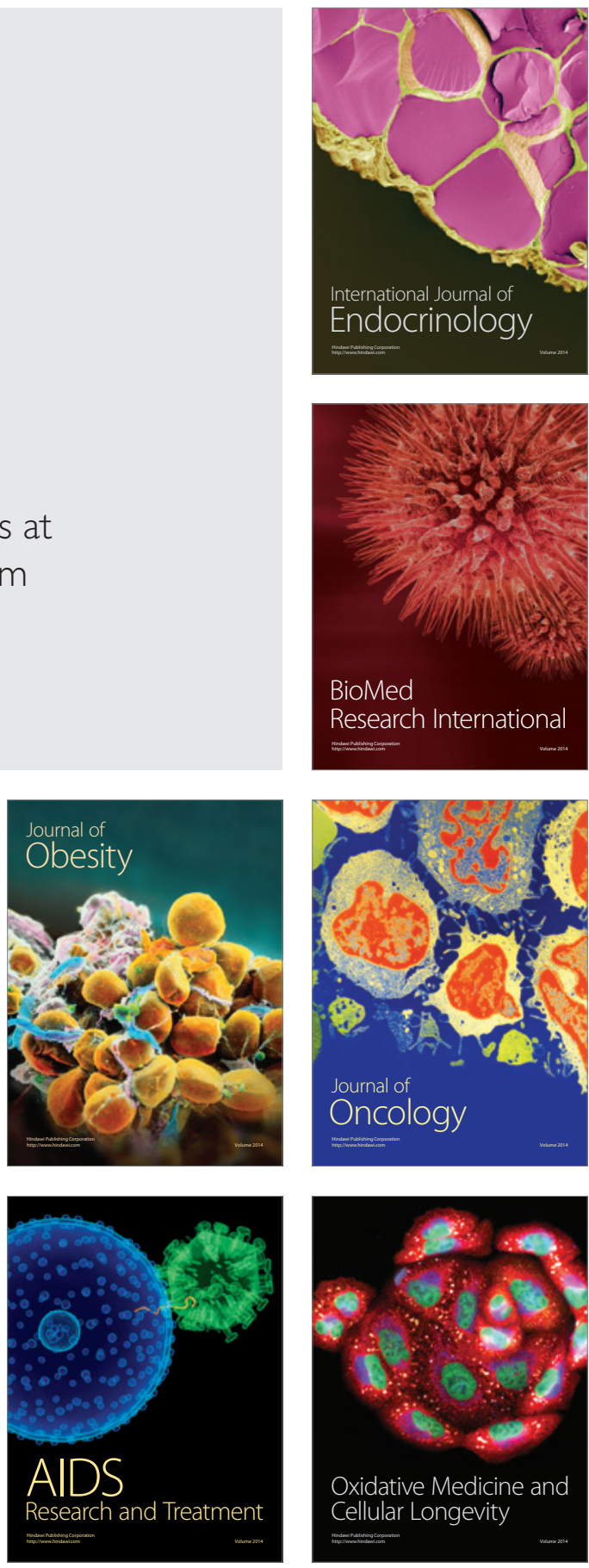